\title{
Gefäßnerven, Tuberkel und Tuberkulinwirkung nach mikro- skopischen Untersuchungen des Bauchfelles beim lebenden Kaninchen und in Flächenpräparaten.
}

\author{
Von \\ G. Ricker und G. Goerdeler. \\ (Aus der Pathologisch-anatomischen Anstalt der Stadt Magdeburg.) \\ Mit 5 Textfiguren und 1 Tafel.
}

(Eingegangen am 2\%. Mai 1914.)

In der vorliegenden Abhandlung haben wir uns bemüht, die Kenntnisse über die Wirkung des Tuberkelbacillus im Bindegewebe und die des Tuberkulins auf normales und tuberkulöses Gewebe zu erweitern. Wenn wir als Versuchsfeld das Bauchfell gewählt haben, so ist dies nicht so sehr geschehen, weil die Bauchfelltuberkulose bisher niemals in gröBerem Maßstabe Gegenstand der experimentellen Forschung gewesen ist, als deshalb, weil sich das Peritoneum des Kaninchens vermöge seiner Durchsichtigkeit einmal im lebenden Tier, zum zweiten in fixierten und gefärbten Flächenpräparaten untersuchen läßt. Von diesen beiden Methoden, die sich gegenseitig aufs beste ergänzen, bedarf die erste als über die Schranken des rein Morphologischen hinausführend keiner besonderen Rechtfertigung; daß aber auch die zweite durch Plastik und Größe des Bildes sowie die Wahrung der Lagebeziehung der Teile vor dem Schnittverfahren außerordentliche Vorzüge hat, haben wir immer wieder aufs angenehmste empfunden und dürfte auch aus den Beschreibungen sowie den Abbildungen bis zu einem gewissen Grade hervorgehen.

Was zunächst die mikroskopische Untersuchung des Mesenteriums im lebenden Kaninchen angeht, so haben wir mit einigen zweckmäßigen Modifikationen das von dem Physiologen W. Kühne (1882) angegebene und zur Erforschung der Sekretionsveränderungen der Pankreaszellen benutzte Verfahren angewandt, bei dem die Tho masche Irrigation mit physiologischer Kochsalzlösung (1878) benutzt wird. Wir haben, wie Kühne und wir selbst in früheren Versuchen, das Duodenalmesenterium, welches beim Kaninchen das durchsichtige Pankreas enthält, gewählt, weil sich die Duodenalschlinge besonders leicht, fast immer mit einem Griff, von einer kleinen seitlichen Laparotomiewunde aus herausholen läßt, und zwar auf einen beliebigen Teil der großen, man kann sagen, übergroßen Länge, die jede Zerrung ausschließt.

Z. f. d. g. exp. Med. IV. 
In der Hand des Geübten - und als solchen darf sich der eine von uns, der vor und bei der gemeinsamen mikroskopischen Untersuchung auch in dieser Versuchsreihe die technischen Maßnahmen getroffen hat, nach Hunderten von (bereits publizierten) Versuchen (die Vorversuche ungerechnet) bezeichnen - arbeitet die Methode einwandfrei, insbesondere so, daB bei stundenlanger Beobachtung der physiologische Charakter der Blutströmung nicht alteriert wird. Wenn wir uns in der uns hier beschäftigenden Versuchsreihe auf sehr kurze Beobachtungszeit beschränkt und eine stärkere Verschiebung der makroskopisch rasch gewählten Stelle meist vermieden haben, so ist das deswegen geschehen, weil in einem Teil der Versuche durch die pathologischen Reize das Gefäßnervensystem in einen sehr empfindlichen Zustand versetzt worden war, so daß die Technik als minimaler, aber nicht zu vernachlässigender Reiz wirken kon nte. Wo sich bei der Beobachtung ein Hinweis auf eine solche Wirkung ergab, ist dies ausdrücklich bemerkt worden. - Im übrigen dürfen wir unsere Beobachtungen in ihrer strengen Abhängigkeit von absichtlich gesetzten Reizen für sich selbst sprechen lassen.

Die Flächen präparate sind so hergestellt worden, daß das Mesenterium, auf Kork gespannt, einen bis zwei Tage in 96\% Alkohol fixiert und dann in Stücke zerlegt wurde, die, mit Carbolfuchsin, Hämalaun, Orange-G gefärbt, im Farrantschen Glyceringemisch eingebettet und untersucht wurden. Man'erhält auf diese Weise eine Färbung der Tuberkelbacillen, der Zellen und der roten Blutkörperchen.

Beide Methoden sind nur anwendbar am Mesenterium fettarmer Kaninchen, junger Tiere von $800-1000 \mathrm{~g}$ Gewicht, bei denen jenes auch im tuberkulösen $\mathrm{Zu}$ stande völlig durchsichtig ist mit Ausnahme der größeren zentral verkästen Knötchen, die wir unberücksichtigt gelassen haben. -

Bei der Wahl des Infizierverfahrens hat uns zunächst der Wunsch geleitet, eine umschriebene Bauchfelltuberkulose zu erzielen. Diese ist auf zwei verschiedene Weisen herbeigeführt worden. Einmal so, daß das Duodenalmesenterium $1 / 2$ Minute lang mit einer Aufschwemmung von $2 \mathrm{mg}$ Reinkultur in $10 \mathrm{ccm}$ physiologischer Kochsalzlösung bepinselt wurde (I. Vers uchsreihe), zum zweiten so, daß das (wie erwähnt sehr große) Duodenalmesenterium auf einer angewärmten, mit physiologischer Kochsalzlösung befeuchteten, horizontal gehaltenen Glasplatte ausgebreitet und mit ungefähr $3 \mathrm{ccm}$ einer Bacillenaufschwemmung ( $2 \mathrm{mg}$ Reinkultur auf $10 \mathrm{com}$ physiologischer Kochsalzlösung) auf 2 Minuten beschickt wurde; die Flüssigkeit wurde dann durch Neigen der Glasplatte entfernt oder mit Gaze aufgesogen, ehe die Schlinge in die Bauchhöhle zurückgebracht wurde (2. Ver suchsreihe).

Bei beiden Verfahren sind, nach den Tuberkeln zu urteilen, nur wenige Bacillen auf anderen Teilen des Bauchfelles zur Ansiedelung gelangt.

In der 3. Versuchsreihe sind $20 \mathrm{ccm}$ physiologiseher Kochsalzlösung, in denen $4 \mathrm{mg}$ Reinkultur fein verteilt waren, in die Bauchhöhle eingespritzt worden.

Es sind vorzugsweise Bacillen vom Typus humanus (Reinkultur auf Glycerinagar) verwandt worden, in der Absicht, eine nicht zu schwere Infektion zu bewirken; wo Bacillen vom Typus bovinus benutzt worden sind, ist dies angegeben.

Bei der so herbeigeführten Bauchfelltuberkulose hat sich niemals Transsudat, Exsudat oder Verwachsung gebildet. In den übrigen Organen sind nur zuweilen spärliche Tuberkel aufgetreten. -

Wie die technischen Einzelheiten des Untersuchungsverfahrens, so können auch die Beobachtungen, die man an der Strombahn und Blutströmung des normalen und des durch Reize beeinflußten Kaninchen- 
mesenteriums macht, hier nicht im einzelnen wiedergegeben werden; es muß auf die früheren Arbeiten verwiesen werden ${ }^{1}$ ). Wohl aber dürfte es zweckmäßig sein, die Gesetze, die das Verhältnis zwischen Reizstärke und Wirkung wiedergeben, hier anzuführen. Die beiden ersten derselben sind in jedem physiologischen Lehrbuch zu finden.

1. Die Dilatatoren werden schon durch schwächere Reize erregt als die Constrictoren.

2. Bei starker Reizung werden die Constrictoren erregt. Bei fortgesetzter oder verstärkter Reizung kann sich die Wirkung eines Reizungszustandes der länger erregbar bleibenden Dilatatoren anschließen.

Nachdem Ricker und Natus in ihren gemeinsamen Versuchen an Pankreas und Mesenterium des lebenden Kaninchens unter dem Mikroskop durch mikrometrische Messung der Gefäßweite diese an anderen Orten im wesentlichen durch elektrische Reizung von verschiedenen Autoren gewonnenen Sätze in bezug auf thermische und zahlreiche chemische Reize bestätigt und außerdem das Verhalten der Geschwindigkeit bei den verschiedenen Reizstärken und Weiten der Strombahn festgestellt hatten, haben sie den weiteren Satz hinzugefügt:

3. Bei fortgesetzter starker Reizung eines gemischten Gefäßnerven in dem Zustande, in dem die Constrictoren ihre Erregbarkeit verloren haben und die Dilatatoren erregt sind, verlangsamt sich die Strömung und steht schließlich still, ein Vorgang, der namentlich bei langsamem Ablauf mit Diapedesisblutung verbunden ist (Stase, Infarzierung).

Um während eines Versuches einen Reiz hervorzubringen oder über das Vorhandensein eines Reizungszustandes der Gefäßnerven unterrichtet zu werden, namentlich in den Fällen, in denen er durch die Besichtigung der Weite der Strombahn und Geschwindigkeit der Strömung nicht auffiel, haben wir Reaktionen angestellt, und zwar mittels Überganges von der körperwarmen physiologischen Kochsalzlösung zu stark abgekühlter Kochsalzlösung oder zu körperwarmer Sublimatlösung ( $1: 20$ 000), oder zu körperwarmer Suprareninlösung (1 : 10000 , wo keine andere Konzentration angegeben). Von diesen Reizen bewirkt beim ge. s̀ unden Tier an den sehr kleinen Arterien, die wir ihrer hohen Erregbarkeit wegen benutzt haben, die Suprareninlösung einen sofortigen Verschluß. Die Sublimatlösung der angegebenen Stärke bewirkt in 10-15 Minuten einen Verschluß der hier in Betracht kommenden kleinen Arterien und 18-20 Minuten nach Beginn der Berieselung Stase. Rascher Übergang zur abgekühlten-Kochsalzlösung hat fast sofortigen Verschluß der kleinen Arterien zur Folge. - Mit den Arterien verschließen sich auf die genannten Reize - mit Ausnahme der Sublimatlösung, die nur eine Verengerung bewirkt - die Capillaren, während sich die Venen nur sehr leicht oder gar nicht verengen und das Blut in ihnen gleichzeitig mit dem Eintritt des Arterienverschlusses stillsteht.

1) Maximilian Natus, Beiträge zur Lehre von der Stase nach Versuchen am Pankreas des lebenden Kaninchens. Virchows Archiv, 199. Bd. 1910. - Versuch einer Theorie der chronischen Entzündung auf Grund von Beobachtungen am Pankreas des lebenden Kaninchens und von histiologischen Untersuchungen nach Unterbindung des Ausführungsganges. Virchows Archiv, 202. Bd. 1910. 
Suprarenin und Sublimat, desgleichen Tuberkulol B und Tuberkulin, sind in physiologischer Kochsalzlösung gelöst auf das Mesenterium gebracht worden.

Zum Verständnis besonders der Protokolle haben wir noch folgendes zu bemerken. Die sehr kleinen Gefäße, die, wie bereits erwähnt, bei den Reaktionsversuchen besonders berücksichtigt worden sind, haben bei Anwendung des fast immer zur Untersuchung des Mesenteriums des lebenden Kaninchens benutzten, durch eine besondere Vorrichtung zur Immersion in die zur Berieselung oder Benetzung dienende Flüssigkeit geeignet gemachten Zei ßschen Apochromatobjektivs $f=16 \mathrm{~mm}$ und bei Kompensationsokular 6 (Vergrößerung 94) ein bis mehrere Intervalle des Okularmikrometers gemessen, von denen bei der Anwendung der genannten Systeme jedes ungefähr $16 \mu$ entspricht. Die (häufig in Klammern) den Gefäßen beigefügten Zahlen brauchen also nur mit 16 multipliziert zu werden, um die Breite in $\mu$ zu ergeben.

Wo im folgenden von neugebildeten Capillaren die Rede ist, sind auch kleinste neugebildete Arterien und Venen mitgemeint, die sich in dem Netz neugebildeter Capillaren zu der Zeit, wo es weitmaschiger wird, aus Capillaren entwickeln.

Die Zeitangaben gelten immer von dem Beginn der Berieselung ab, sei es mit physiologischer Kochsalzlösung, sei es mit einer anderen Flüssigkeit.

Unter Kochsalzlösung ist stets physiologische $(0,9$ proz.) zu verstehen.

Mit der Herkunft der bei der Tuberkulose vermehrt im Mesenterium auftretenden Zellen haben wir uns nicht besonders befaßt. Wir unterscheiden im folgenden fixe (Bindegewebs-) Zellen und ihre Abkömmlinge gleichen Aussehens, Lymphocyten: Zellen vom Aussehen der Lymphocyten des Blutes, der Lymphe, der Lymphdrüsen, polymorphkernige Leukooyten, die wie die im Blute befindlichen und so bezeichneten Zellen aussehen; unter der Bezeichnung polymorphkernige Leukocyten wollen wir auch die multinucleären mitverstanden wissen. Von den polymorphkernigen und multinucleären Leukocyten und mindestens einem großen Teil der Lymphocyten im Gewebe sind wir auf Grund unserer Beobachtungen am lebenden Tier überzeugt, daß sie aus der Blutbahn ins Gewebe befördert worden sind.

Der Kürze halber ist zuweilen von Infiltratzellen gesprochen worden, hierunter sind die ins Bindegewebe mit seinen vermehrten Bindegewebszellen extravasierten polymorphkernigen und multinucleären Leukocyten und die Lymphocyten verstanden.

Vom Serosaepithel haben wir - in Bestätigung der Angaben anderer Autoren - durch die Silberreaktion festgestellt, daß es unverändert über die Tuberkel - mit Ausnahme des zentralen zerfallenen Teils größerer - hinwegzieht, offenbar also nicht an der Tuberkelbildung teilnimmt.

Auf Mitosen haben wir nicht besonders geachtet; wo sie aufgefallen sind, haben wir sie erwähnt.

Die in den Protokollen hinter "Mikroskopisch" verzeichneten Befunde sind ausschließlich am lebenden Tier erhoben.

\section{Teil.}

\section{Erste Versuchsreihe (Aufpinselung tuberkelbacillenhaltiger Flüssigkeit).}

1. Versuch. Beobachtung 2 Tage nach der Infektion.

Makroskopisch: An verschiedenen Stellen allerfeinste graue Fleckchen sichtbar. 
Mikroskopisch: Mesenteriales Bindegewebe im ganzen locker von Zellen durchsetzt. Die Gefäßchen sind weit, geschlängelt, langsam durchströmt. Von ihnen gehen in Arkaden neugebildete Capillaren aus, doch nicht in sehr großer Zahl und Ausdehnung; vereinzelte Capillaren mit Stase, sehr spärliche Ekchymosen. Die oben erwähnten feinsten grauen Flecke sind Zellhäufchen von nicht ganz scharfer Begrenzung und frei von Capillaren.

Reaktionsversuch mit Kochsalzlösung von $+4^{\circ} \mathrm{C}$. Fast momentan nimmt die Verlangsamung des Blutstromes in den Gefäßen zu, die Arterie erweitert sich von $11 / 2$ auf 2 Intervalle. Nach 3 Minuten fast völlige, nach 5 Minuten völlige Stase.

Flächenpräparat: Die das mesenteriale Bindegewebe durchsetzenden Zellen sind vorwiegend einkernige Leukocyten; aus solchen sind auch die Knötchen zusammengesetzt. Capillarneubildung bestätigt.

Bacillen: Das von einem Parallelversuch (mit gleichem Verlauf und Befunde) stammende Mesenterium enthält Bacillen sowohl an veränderten als unveränderten Stellen; die Knötchen enthalten bald zahlreiche, bald spärliche Bacillen.

2. Versuch: Beobachtung 4 Tage nach der Infektion.

Makroskopisch: Eine Anzahl kleinster Ekchymosen und kleinster grauer Fleckchen.

Mikroskopisch: Es finden sich ziemlich zahlreiche kleinere und größere, scharf umschriebene Zellhäufchen, von denen einige zentral trüb aussehen. Ein großer Teil der Knötchen enthält Capillaren, hier und da Stase in diesen. Vereinzelte Ekchymosen.

Genauere Beschreibung eines makroskopisch sichtbaren Knötchens in einiger Entfernung von Fettgewebe: Von diesem her verlaufen parallel eine Arterie (1) und eine Vene $(11 / 2)$, beide geschlängelt, die Vene mehr als die Arterie, beide mit verlangsamt fließendem Blut, das sich in der Arterie vom Fettgewebe entfernt, in der Vene zu diesem hin bewegt. In dem Tuberkel geht die Arterie in ein Capillarnetz über, das sich durch das ganze Knötchen mit Ausnahme des äußersten Teils erstreckt und in die Vene übergeht; die Capillaren sind teils sehr weit, teils sehr eng, Stase fehlt; dagegen kommen in der Nachbarschaft des Tuberkels Stasecapillaren und Ekchymosen vor.

Nachdem sich die Strömung in diesem Knötchen in 20 Minuten nicht verändert hatte:

Reaktionsversuch mit Sublimatlösung an der Gegend mit dem geschilderten Knötchen: Nach 4 Minuten, ohne daß Verengerung aufgetreten wäre, die ersten Stasecapillaren. Nach 9 Minuten fließt das Blut nur noch in der Arterie und Vene und in einigen weiten, die beiden Gefäße verbindenden Capillaren. Nach 10 Minuten Arterie auf $3 / 4$ (von 1) verengt. Nach 11 Minuten Stase allgemein.

Flächenpräparat: Das mesenteriale Bindegewebe diffus durchsetzt mit Lymphocyten und polymorphkernigen Leukocyten; die Kerne dieser meist zu Chromatinkörnchen zerfallen. Die fixen Zellen vergrößert, epithelioid. Die locker gefügten, ziemlich scharf begrenzten Tuberkel bestehen aus den Zellen der angegebenen Art, an der Peripherie in leicht konzentrischer Anordnung. In einigen Knötchen Riesenzellen, wenn auch keine typischen. - Capillarneubildung bestätigt.

Bacillen: In den Knötchen einzelne Bacillen und Züge von solchen, sowohl in Zellen als außerhalb von solchen. Das diffuse Zellinfiltrat teils bacillenhaltig, teils bacillenfrei.

3. Versuch: Beobachtung 6 Tage nach der Infektion.

Mikroskopisch: Im ganzen Mesenterium der Duodenalschlinge Zellinfiltration und Capillarneubildung; einzelne Stasecapillaren und Ekchymosen. 
Genauer beobachtet wird ein achterförmiger Zwillingstuberkel zwischen 2 parallel verlaufenden geschlängelten Venen, die er mit seinen beiden Hälften berührt. In der Mitte zwischen beiden Venen, die 2 und 1 Teilstriche messen und langsam durchströmt sind, eine Arterie ( $1 / 2$ Teilstrich), die in die eine Hälfte des Zwillingstuberkels eintritt. Dieser ist durchzogen von einem Capillarnetz, das mit den beiden Venen zusammenhängt und in das sich die Arterie auflöst. Im Doppeltuberkel einige allerkleinste Ekchymosen. Während einer Beobachtungs. zeit von 10 Minuten ändert sich nichts an der langsamen Strömung.

Reaktionsversuch mit abgekühlter Kochsalzlösung von $+10^{\circ} \mathrm{C}$ auf 2 Minuten, dann von $+5^{\circ}$. Nach gut 4 Minuten zunehmende Verlangsamung der Blutströmung; nach 8 Minuten einige Capillaren mit Stase. Nach 20 Minuten sind nur noch die nahe der Arterie gelegenen Capillaren durchströmt, im übrigen Stase. Die Ekchymosen sind etwas größer geworden. - Nunmehr Berieselung mit Kochsalzlösung von $38^{\circ}$ : nach 5 Minuten ist die Strömung wieder wie vor dem Reaktionsversuch.

4. Versuch: Beobachtung 6 Tage nach der Infektion.

Es werden eingestellt eine Arterie $(1+)$ und eine dicht daneben verlaufende Vene $(1 / 2)$. Von der Vene entspringen nahe beieinander zwei weite stark geschlängelte, von der Arterie eine einzige leicht geschlängelte Capillare; nach getrenntem Verlauf durch eine Strecke des Mesenteriums gehen die drei Ästchen in ein weitmaschiges Capillarnetz über, das sich durch einen außerordentlich scharf begrenzten Tuberkel hindurch erstreckt. Am Rande desselben mehrere kleine Ekchymosen.

Reaktionsversuch mit Suprareninlösung $1: 1000$ : in vier Minuten tritt keine Änderung auf, außer daß die Ekchymosen etwas größer werden.

Nunmehr wird an der entgegengesetzten Körperseite des Tieres eine Dünn. darmschlinge hervorgeholt und ihr unverändertes Mesenterium mit einer gleich. starken Suprareninlösung berieselt: schwache Verengerung der eingestellten Arterie und Verlangsamung des Venenstromes; nach 1 Minute Verschluß der Arterie. Der Verschluß verschwindet zeitweise bei fortgesetzter Berieselung.

Sektionsergebnis: Sehr zahlreiche mohnkorngroße und etwas größere Tuberkel in dem ganzen Bauchfell mit Ausnahme des parietalen Blattes.

Schnittpräparate: Diffuse sehr starke Durchsetzung des Mesenteriums mit polymorphkernigen Leukocyten und mit Lymphocyten. Sehr vereinzelte kleinste Bacillenhäufchen, z. T. anscheinend in Zellen.

Flächenpräparat: Diffuses Infiltrat von Lymphocyten und polymorph. kernigen Leukocyten im Mesenterium. Sehr zahlreiche kleine scharf begrenzte, z. T. im Zentrum trübe, hier und da in Gruppen stehende oder verschmolzene Tuberkel. Die Tuberkelzellen ziemlich groß, einkernig, Kern z. T. hufeisenförmig; keine mehrkernigen Zellen; die Tuberkelzellen sehen leicht geschrumpft aus. Neugebildete Capillaren, die auch durch Tuberkel hindurchgehen. Tuberkel auch in gänzlich capillar- und gefäßfreien Gebieten. Nirgends Bacillen.

5. Versuch: Beobachtung 11 Tage nach der Infektion.

Mikroskopisch: Mesenteriales Bindegewebe stark mit Lymphocyten und polymorphkernigen Leukocyten durchsetzt; außerordentlich starke und ausgedehnte Capillarneubildung. An einzelnen Stellen scharf umschriebene Zellhaufen. Ein solcher Tuberkel, im Zentrum trüb, mit einem Saum neugebildeter Capillaren an der Peripherie und zwei kleinen Ekchymosen in der Nähe, wird verwandt zum

Reaktionsversuch mit Suprareninlösung 1 : 2000: Weder die Arterie noch die Vene, an deren Kreuzungsstelle der Tuberkel liegt, noch die erwähnten Capillaren dieses ändern ihre Weite und (geringe) Geschwindigkeit. Dagegen bringt dieselbe Suprareninlösung die Arterien im - unveränderten - Mesenterium einer Dünndarmschlinge aus der entgegengesetzten Bauchhälfte sofort zum Ver- 
schluB. - Die Besichtigung des gesamten Mesenteriums der Duodenalschlinge am Schlusse des Versuchs ergibt, daß während desselben in der Umgebung der vorhandenen Tuberkel Stasecapillaren und einzelne kleinste Ekchymosen aufgetreten sind.

Sektion: Wenige große käsige, mit einem roten Hof versehene Tuberkel im Mesenterium der dem Duodenum benachbarten Schlingen.

6. Versuch: Beobachtung 13 Tage nach der Infektion (mit Bacillen vom Typus bovinus).

Mikroskopisch: Die zu genauerer Untersuchung gewählte Stelle zeigt folgendes: Eine Arterie (2) und eine Vene, beide gestreckt, verlaufen parallel miteinander, verbunden durch ein Netzwerk neugebildeter Capillaren. An die Vene schließt sich auf der der Arterie abgewandten Seite ein Tuberkel mit trübem Zentrum, umsponnen von einem Capillarnetz, das mit dem zuerst erwähnten zusammenhängt; im Tuberkel selbst keine Capillaren sichtbar. Die Capillaren teils schnell, teils langsam durchströmt; die Arterienströmung rasch, die Venenströmung etwas langsam. Eine kleine Ekchymose in größter Eṇtfernung vom Tuberkel. Keine Stasecapillaren.

Reaktionsversuch mit Sublimatlösung: nach 3 Minuten Verlangsamung der Strömung, einige Stasecapillaren und eine Ekchymose treten auf. Die Arterie hat ihre ursprüngliche Weite behalten. Nach etwa 10 Minuten ist die Stase allgemein, nur in der Arterie und Vene noch stark verlangsamterStrom. Mehrere Ekchymosen. Unter Berieselung mit Kochsalzlösung bleibt die Capillarstase bestehen, die.Ekchymosen werden größer.

Berieselung des unveränderten Mesenteriums einer entfernt gelegenen Dünndarmschlinge mit Sublimatlösung: Nach 19 Minuten starke Verengerung der Arterie, vollständige Entleerung der Capillaren, das Venenblut steht still. Dieser Zustand bleibt bei längerer Berieselung mit Kochsalzlösung bestehen.

7. Versuch: Beobachtung 14 Tage nach der Infektion (mit Bacillen vom Typus bovinus).

Mikrosko pisch: Von zwei eng benachbarten, normal durchströmten Gefäßen (Arterie 3, Vene 2) geht je ein leicht geschlängelter Ast aus, der sich weiter verzweigt bis an einen ovalen, am einen Pol scharf, am anderen undeutlich begrenzten Zellhaufen heran, der von einem Arterienast und von Venenästchen durchzogen ist; er ist umgeben von einem teils engmaschigen, teils weiten Capillarnetz, das sich in die entferntere Nachbarschaft fortsetzt und sehr langsam durchströmt ist. Die Venenästchen sind von extravasierten Leukocyten umgeben. Während der gut einstündigen Beobachtung bleibt die Strömung unverändert.

Reaktionsversuch mit Sublimatlösung: Sofortige Entleerung der Arterienäste und Capillaren, die sich während der 5 Minuten langen Einwirkung der Lösung hält. Nach Ủbergang zur Berieselung mit Kochsalzlösung tritt rasch allgemeine Erweiterung und Stase ein.

In Schnittpräparaten sind die Bacillen sehr spärlich.

8. Versuch: Beobachtung 25 Tage nach der Infektion.

Mikroskopisch: Makroskopisch eben sichtbaren grauen Fleckchen entsprechen meist undeutlich begrenzte, oft im Zentrum trüb aussehende Zellhaufen; sie liegen in einem sehr weitmaschigen Capillarnetz, und zwar so, daß die Capillaren durch die Randpartien der Knötchen hindurchziehen. Die Capillaren sind teils schnell, teils langsam durchströmt, sie gehen von schnell durchströmten geschlängelten Mesenterialgefäßen aus. Während des Versuches treten am Rande eines Tuberkels Ekchymosen auf, die sonst, ebenso wie Stasecapillaren, fehlen.

Reaktionsversuch mit Suprareninlösung 1 : 2000 an einem scharf hervortretendem Tuberkel nahe einer Arterie (1) und einer Vene $(1+)$ mit schnellem Strom. Nach 3 Minuten beginnt zunächst in einzelnen Capillaren Stase und breitet 
sich dann aus. Nach 4 Minuten Arterie leicht erweitert, Strömung stark verlangsamt.

Während der nun folgenden Berieselung mit Kochsalzlösung stellte sich die Strömung nicht wieder her.

9. Versuch: Beobachtung 25 Tage nach der Infektion.

Mikrosko pisch: Im ganzen derselbe Befund wie beim vorhergehenden Tiere; die kleinsten Tuberkel sind nicht von Capillaren durchzogen, sondern berühren nur Capillaren oder liegen ganz entfernt von solchen. Auch kleinste Tuberkel sind im Zentrum leicht getrübt.

Reaktionsversuch mit Sublimatlösung an einer Stelle mit Tuberkel und einem in mittlerer Geschwindigkeit durchströmten Capillarnetz, das von leicht geschlängelten und leicht verlangsamt durchströmten Gefäßchen ausgeht. Nach 3 Minuten bewegen sich im Venenblut in regelmäBigen Abständen kleine weiße Pfröpfe. Nach 4 Minuten deutliche Stromverlangsamung in einzelnen Venenästchen; die Capillaren anscheinend leicht verengt. Nach 5 Minuten die erste Stasecapillare. Nach 7 Minuten Arterie verengt, die Stase wird allgemein.

Flächenpräparat: Das mesenteriale Bindegewebe an Zellen vermehrt. Die Zahl der Capillaren nicht sèhr beträchtlich, geringer als bei den früheren Tieren. Die Tuberkel sehr zahlreich, scharf begrenzt, z. T. unter sich verschmolzen, nur ein kleiner Teil der größeren von Capillaren durchzogen. Sehr vereinzelte Bacillen in den Knötchen.

10. Versuch. 1. Beobachtung 7 Tage nach der Infektion.

Makroskopisch: Eine mäßige Anzahl von grauen Knötchen im Mesenterium der Duodenalschlinge, die größten gut mohnkorngroß. Schon beim ersten Blick auf die heraustretende Sohlinge sieht man Ekchymosen in der Nähe von Knötchen.

Mikroskopisch: Die im Zentrum trüben Knötchen sind von einem Netz sehr weiter, teils langsam durohströmter, teils mit stillstehendem Blut versehener Capillaren umgeben; in der weiteren Umgebung weist das Mesenterium keine Capillaren auf. Während der Beobachtung treten Stasecapillaren und Ekchymosen auf.

Reaktionsversuch mit Sublimatlösung an einer Stelle ohne neugebildete Capillaren, entfernt von Tuberkeln, mit einer rasch durchströmten Arterie $(1+)$. Nach 4 Minuten geringe Verengerung der Arterie; eine benachbarte etwas größere Arterie segmentär verengt. Nach 10 Minuten Stase. Versenkung der Darmschlinge, Naht.

2. Beobachtung 27 Tage nach der Infektion.

Das Mesenterium der infolge von partieller Verwachsung nur z. T. heraustretenden Schlinge diffus getrübt und etwas verdickt. Es fallen einzelne größere käsige Knötchen auf.

Mikroskopisch: Zellen des mesenterialen Bindegewebes stark vermehrt, an mehreren Stellen zu nicht scharf abgesetzten Häufchen gruppiert. Überall ein Netz enger, teils schnell, teils langsam durchströmter Capillaren, die spärlicher sind, als bei den früheren Tieren. Keine Stasecapillaren. Keine Ekohymosen. Es wird nun eine entfernt vom Duodenum gelegene Dünndarmschlinge herausgeholt und ihr Mesenterium untersucht: Viele kleinste scharf begrenzte Tuberkel, die einen capillarfrei, die anderen mit Capillaren in der Randpartie.

Reaktionsversuch mit Sublimatlösung an einer Stelle des Dünndarmmesenteriums, wo ein Venenästchen über einen Tuberkel hinwegzieht und in einiger Entfernung von diesem in ein weitmaschiges Capillarnetz übergeht. Ein in der Nähe gelegenes Gefäßpaar etwas langsam, die Capillaren rasch durchströmt. Nach 1 Minute Verlangsamung des Venen-, und bald auch des Capillarstromes. Nach 2 Minuten Stase in einzelnen Capillaren. Nach 6 Minuten Stase allgemein. 
Sektionsbefund: Zahlreiche eben sichtbare bis fast stecknadelkopfgroße käsige Tukerkel in der Darmserosa und im Netz. Leber, Milz, Lungen frei von Tuberkeln.

Flächenpräparat: Derselbe Befund wie beim vorigen Tier, doch keine Bacillen nachweisbar. Keine Riesenzellen.

In der ersten Versuchsreihe ist die die Tuberkelbacillen in feiner Verteilung enthaltende Flüssigkeit mit einem weichen Pinsel auf das Duodenalmesenterium aufgetragen worden. Aus den Protokollen heben wir im folgenden das wichtigste hervor.

Schon nach 2 Tagen sind die ersten feinsten Knötchen sichtbar gewesen, bestehend aus vorwiegend einkernigen Leukocyten, wie sie auch diffus das mesenteriale Bindegewebe durchsetzten. Die Strombahn war zu dieser Zeit weit, langsam durchströmt, die geschlängelten Gefäßchen hatten erst in geringem Grade Capillaren aus sich hervorgehen lassen, in denen hier und da das Blut stillstand und aus denen stellenweise rote Blutkörperchen ausgetreten waren.

Beträchtlicher ist die Zahl der Knötchen nach 4 Tagen gewesen, auch die Größe vieler hatte zugenommen, die Capillarneubildung war stärker geworden, nicht minder die Durchsetzung des mesenterialen Bindegewebes mit Leukocyten, von denen die polymorphkernigen bereits Zerfallsveränderungen zeigten. Auch viele Tuberkel enthielten in ihrem Inneren neugebildete Capillaren, in denen das Blut nicht selten stille stand; eine Anzahl der Tuberkel war bereits im Zentrum getrübt. In den geschlängelten Gefäßchen des Mesenteriums floß das Blut noch immer verlangsamt; Stasecapillaren und Ekchymosen waren selten. Die fixen Zellen waren zu dieser Zeit deutlich vergrößert, aus ihnen und aus Leukocyten waren die Knötchen aufgebaut.

6 Tage nach der Infektion haben wir einen Doppeltuberkel beschrieben, der in seinen beiden Hälften ein (neugebildetes) Capillarnetz besaß, das mit benachbarten Venen und einer kleinsten Arterie zusammenhing.

Noch auffälliger war die Capillarversorgung der Tuberkel in dem folgenden, ebenfalls 6 Tage nach der Infektion gewonnenem Präparat: hier war ein größerer Tuberkel von einem eigenen, neugebildeten Capillarnetz durchzogen, das einen arteriellen Zufluß und zwei venöse $A b$ flüsse, alle drei ebenfalls neugebildet, besaß. Wie in Präparaten aus früherer Zeit waren auch hier im Bereich des Tuberkels Ekchymosen vorhanden. Das mesenteriale Bindegewebe war 6 Tage nach der Infektion noch stark mit Leukocyten durchsetzt. Die aus einkernigen Zellen zusammengesetzten Tuberkel waren zahlreich, teils capillarhaltig, teils capillarfrei und in capillarfreier Umgebung gelegen.

11 Tage nach der Infektion war die Capillarneubildung und die Durchsetzung des mesenterialen Bindegewebes mit Leukocyten noch 
stärker. Nur in ihrem peripherischen Teil waren die Tuberkel mit einem Kranz neugebildeter Capillaren versehen, in dessen Bereich Ekchymosen vorkommen konnten. Die zum Teil sehr großen Tuberkel waren nicht selten im Zentrum getrübt.

Von dem folgenden Stadium, 13 Tage nach der Infektion, ist hervorzuheben, daß die Gefäßchen nun nicht mehr geschlängelt, sondern gestreckt und nicht mehr verlangsamt durchströmt waren; in den Capillaren wechselte die Geschwindigkeit der Strömung. Die vorher zahlreichen Stasecapillaren fehlten; es war im Gegensatz zu früheren Zeiten, wo sie häufig waren, nur eine kleine Ekchymose vorhanden. Der beobachtete zentral getrübte Tuberkel war wieder umsponnen von einem Capillarnetz, im Innern frei von Capillaren.

Im wesentlichen derselbe Befund ist am 14. Tage erhoben worden.

Aus den Beobachtungen am 25. Tage ist hervorzuheben, daß das Netzwerk neugebildeter Capillaren in dem an fixen Zellen vermehrten mesenterialen Bindegewebe nun bedeutend weitmaschiger war, als zu früheren Zeiten; meist nur durch die Randteile von Tuberkeln zogen $\mathrm{Ca}$ pillaren hindurch. Auch auf diesem Stadium war die Strömung in den Gefäßchen schnell, die in den Capillaren teils schnell, teils langsam. Stasecapillaren und Ekchymosen fehlten auch hier. Ein 2. Versuch an einem vor 27 Tagen infizierten Mesenterium bestätigte diese Beobachtungen; bei demselben Tiere waren 7 Tage nach der Infektion die Ekchymosen nahe den Knötchen zahlreich gewesen.

Mit der größeren Zeitdauer seit der Infektion sind die Tuberkel schärfer begrenzt worden.

Was die Bacillen anbetrifft, so enthielten die bereits am 2. Tage sichtbar gewesenen Knötchen bald zahlreiche, bald spärliche Bacillen, doch fanden sich solche, so kurze Zeit nach der Infektion, auch an ganz unveränderten Stellen des Mesenteriums. Auch nach 4 Tagen wechselte der Bacillengehalt der Knötchen; außerhalb der Knötchen, in dem diffusen Zellinfiltrat, waren an der einen Stelle Bacillen nachweisbar, an der anderen nicht. Auffällig gering war die Zahl der Bacillen und kleinsten Bacillenhäufchen in dem 6 und in dem 14 Tage nach der Infektion gewonnenen Mesenterium. Noch auffälliger ist die Beobachtung, daß zwar in dem 25 Tage nach der Infektion gewonnenen Präparat Bacillen, wenn auch sehr vereinzelte, in den Tuberkeln nachweisbar gewesen sind, daß sie aber 27 Tage nach der Infektion in den - ausschließlich kleinen - Tuberkeln des Flächenpräparates vermißt wurden.

In bezug auf den Ausfall der Versuche, in denen wir die Reaktion der alten und der neugebildeten Gefäßchen und Capillaren gegen einen physikalischen Reiz - Kälte - und gegen chemische Reize - Suprarenin und Quecksilbersublimatlösung - geprüft haben, ist als vorwiegendes Ergebnis anzuführen, daß die Verengerung, die die genannten Reize 
an einer normalen Strombahn hervorbringen, ausgeblieben und nach vorheriger Erweiterung der Strombahn und Verlangsamung des Blutstromes Stase durch Sublimatlösung stark verfrüht herbeigeführt worden ist, während die anderen Reize ebenfalls rasch Stase bewirkten, obwohl sie dazu in den bisher angewandten Zeiten gegenüber einer normalen Strombahn überhaupt nicht imstande sind. Nur im 7. Versuch (14 Tage nach der Infektion) und im 9. (25 Tage nach derselben) ist auf Sublimat eine Verengerung aufgetreten, im 9 . Versuch verspätet, bei schon beginnender Capillarstase. -

Wenn wir auf diese Angaben vergleiohend zurückblicken, so ergibt sich, daß die Wirkung des Eingriffes in zwei Perioden zerfällt.

In der ersten, vóm frühesten Versuch, 2 Tage nach der Infektion, bis zum 5. Versuch, 11 Tage nach derselben, reichend, haben wir eine Erweiterung der Strombahn und Verlangsamung des Blutstromes, Extravasation von Leukocyten einerseits, Stasecapillaren und Ekchymo'sen andererseits festgestellt, ferner eine zunächst geringe, dann sehr beträchtliche Neubildung von Capillaren, die außerhalb und nach dem 3. Tage auch innerhalb der Tuberkel gelegen waren.

In der zweiten Periode, vom 13.-25. Tage nach der Infektion, war die Weite der Strombahn und die Geschwindigkeit der Blutströmung wieder der Norm angenähert, die extravasierten Zellen und die neugebildeten Capillaren außerhalb und innerhalb der Tuberkel weit spärlicher als vorher; Stasecapillaren und Ekchymosen haben gefehlt. Auch die Reaktion gegen künstliche Reize wich - allerdings nur in 2 der angestellten Versuche - weniger von der an einer normalen Strombahn auftretenden ab, als in der ganzen ersten Periode.

\section{Źweite Versuchsreihe (Benetzung mit tuberkelbacillenhaltiger Flüssigkeit).}

1. Versuch: Beobachtung $3 / 4$ Tage nach der Infektion.

Makroskopisch: Ein zwischen zwei großen mesenterialen Gefäßen liegender Abschnitt des Mesenteriums ist leicht getrübt.

Mikroskopisch: In diesem trüben Teil starke Zellvermehrung, in den übrigen Teilen nur geringe, am deutlichsten in der Nähe des Fettgewebes. Das Blut fließt in den Arterien und Venen verlangsamt.

Reaktionsversuch mit Suprareninlösung: Nach einer halben Minute Arterie (1) auf einen Moment verengt, sie wird dann wieder weit, eher erweitert. Nach einer Minute Verlangsamung des Arterien- und Venenstromes, nach 21/2 Minute Stillstand des Venenblutes, fast völliger Stillstand des Arterienblutes; Arterie 1 t. Nunmehr Berieselung mit Kochsalzlösung: Nach 6 Minuten beginnt in der Arterie und Vene die Strömung wieder, nach 8 Minuten ist sie wieder hergestellt, wenn auch etwas verlangsamt.

Flächen präparat: Die vermehrten Zellen sind polymorphkernige Leuko. cyten. Von den präexistierenden Capillaren sieht man sehr zahlreiche Sprossen ins Mesenterium ausstrahlen und zugespitzt endigen. Venen geschlängelt, die Leukocyten im Venenblut vermehrt. An der Grenze einer Gruppe von Capillaren 
und Capillarsprossen vereinzelte dichte, scharf begrenzte, vorwiegend aus mehrkernigen Zellen bestehende kleinste Zellhäufchen; die Capillaren und Sprossen derselben erstrecken sich an einer Stelle in die Randzone des Häufchens hinein.

In einem dieser Zellhäufchen eine Anzahl von Bacillen, sonst im Gewebe keine Bacillen.

2. Versuch: Beobachtung 1 Tag nach der Infektion.

Makroskopisch: In einigen Quadranten feinste weiße Pünktchen sichtbar.

Mikroskopisch: Annähernd gleichmäBige Zellvermehrung. Keine neugebildeten Capillaren. Eine Anzahl Venen geschlängelt, mit verlangsamtem Strom und vermehrten, stark verlangsamt bewegten randständigen Leukocyten.

Reaktionsversuch mit Suprareninlösung: Sehr bald tritt streckenweise Verengerung der Arterie (1) auf. Nach 2 Minuten starke Verlangsamung des Venenblutes, Arterie noch nicht verschlossen. - Berieselung mit Kochsalzlösung: Nach etwa 1 Minute ist die Arterie völlig verschlossen.

Flächen präparat: Fixe Zellen vergrößert. Sehr zahlreiche polymorphkernige Leukocyten im Mesenterium, besonders zahlreich in der Umgebung der kleinen Venen. Hier und da Knötchen, teils allerkleinste, teils makroskopisch eben sichtbare. Die kleinsten bestehen aus den beiden genannten Zellarten, besonders aus polymorphkernigen Leukocyten, in dichter Lagerung. An den großen Knötchen kann man die beiden Zellarten nur an der Peripherie unterscheiden, während im Zentrum eine dichte, nicht $\mathrm{zu}$ analysierende Masse zu sehen ist. Grenze der Knötchen scharf. In ihrer Nähe sind die polymorphkernigen Leukocyten zahlreicher als in weiterer Entfernung.

In den kleinen Knötchen spärliche Bacillen; ein kleines gut durchsichtiges Knötchen ohne Bacillen. Im zentralen Teil einzelner großer Knötchen Bacillenhaufen. Außerhalb der Knötchen keine Bacillen.

3. Versuch: Beobachtung 3 Tage nach der Infektion.

Makroskopisch: Einzelne über hirsekorngroße käsige Knötchen.

Mikrosko pisch: Zahlreiche Zellen vorwiegend um die geschlängelten Venen und im Bereich der neugebildeten Capillaren. Ein zentral trüb aussehender Zellhaufen nahe einem neugebildeten Capillarnetz, das von einer scharf begrenzten Strecke einer stark geschlängelten Vene ausgeht; ein Teil der neugebildeten Capillaren reicht in die peripherische Zone des Zellhaufens hinein, der im übrigen ganz in capillarfreiem Mesenterium liegt und selbst capillarfrei ist. Ähnlich liegen andere Zellhäufchen.

Reaktionsversuch mit Suprareninlösung nahe einem Knötchen: Nach I Minute Arterie erweitert, Strom in ihr und in der Vene verlangsamt. Nach 2 Minuten Strom in der Arterie und Vene umgekehrt. Nach 21/2 Minute Strom sehr träge, bei noch erweiterer Arterie. Kochsalzlösung: Nach 11/2 Minuten völlige Stase.

2. Reaktionsversuch an anderer Stelle: Nach 1 Minute an einer Strecke der Arterie Verengerung, nach knapp 2 Minuten Verlangsamung des Arterienstromes bei unveränderter Weite. Nach 4 Minuten Stase, bei sehr erweiterter Arterie. Die Stase des Berieselungsfeldes wird erst unter Kochsalzberieselung vollständig.

Flächen präparat: Die polymorphkernigen Zellen sind zahlreicher als bei den bisherigen Tieren. Die fixen Zellen vergrößert und hier und da $2-3$ kernig. Die Netze neugebildeter Capillaren gehen von den größeren Venen aus. In bezug auf die Knötchen kein Unterschied gegen den Befund bei den vorhergehenden Tieren.

Bacillen: Allerkleinste Knötchen mit Bacillen im Zentrum, etwas größere mit Bacillenhäufchen auch in der Peripherie; hier und da Bacillenhäufchen ohne Knötchenbildung.

Sektion: Auf der Serosa des Blinddarmes vereinzelte überhirsekorngroße graugelbliche Knötchen. 
4. Versuch: Beobachtung 4 Tage nach der Infektion.

Mikroskopisoh: Diffuse Zellvermehrung, im allgemeinen keine Knötchen Große Strecken des Mesenteriums frei von neugebildeten Capillaren. Zahlreiche kleine stark geschlängelte Venen im Mesenterium sind von etwas stärker vermehrten Zellen umgeben und weisen capilläre Sprossen auf, z. T. mit Stase. Andere stark geschlängelte, langsam durchströmte, mit vermehrten Randkörperchen versehene Venen sind von einem ganzen Netz neugebildeter Capillaren umgeben, die z. T. Stase, auch mit bereits entfärbtem Inhalte, aufweisen. Nahe einer solchen Vene ein erstes und nicht weit davon an der Kreuzungsstelle derselben mit einem Arterienast, der mit der zugehörigen Vene ebenfalls von einem Netz neugebildeter Capillaren umgeben ist, ein zweites tuberkelähnliches, mit Capillaren versehenes Zellhäufchen. - Ưberall Strömung langsam.

Reaktionsversuch mit Suprareninlösung in der Gegend des zweiten Knötehens: Bei 2 Minuten langer Berieselung keine Veränderung an der beobachteten Arterie, außer daß stellenweise leichte Einschnürung auftritt.

Flächen prä parat: Sehr starke und zwar ungleichmäßige Vermehrung der fixen Zellen; vereinzelte polymorphkernige Leukocyten und Lymphocyten eingestreut. Bäumchen neugebildeter Capillaren von Venchen ausgehend.

Von zwei kleinsten Knötchen, bestehend aus epithelioiden Zellen ohne deutliche Capillaren, enthält eines Bacillen, das andere keine. Ein größeres, im Zentrum etwas zerfallenes Knötchen enthält im Inneren zwei kleinste Fremdkörper, in deren Nähe Bacillen liegen. Bacillen auch im peripherischen Teil dieses Knötchens. Außerhalb der Knötchen keine Bacillen im Gewebe.

5. Versuch: Beobachtung 5 Tage nach der Infektion.

Makroskopisch: Hier und da mohnkorngroße gelbliche Knötchen.

Mikroskopisch: Im allgemeinen diffuse Zellvermehrung. Es kommen eben erkennbare trübe Fleckchen im Mesenterium vor; ein solches, von locker gelagerten Zellen umgeben, zwischen denen neugebildete Capillaren liegen, wird genauer untersucht. Die Capillaren dieses undeutlich begrenzten Zellhäufchens sind vorwiegend durchströmt, zum kleineren Teil besteht in ihnen Stase; sie gehen von einer stark geschlängelten durch das Knötchen hindurchverlaufenden Vene mit trägem Strom $(1+)$ aus, die eine gestreckt verlaufende Arterie, an der sich keine Capillaren gebildet haben, kreuzt. Im allgemeinen sind die Netze neugebildeter Capillaren auf umschriebene Strecken der Venen beschränkt, daselbst aber sehr beträchtlich, in Form eines Mantels um den betreffenden Abschnitt der stark geschlängelten Vene ausgebildet.

Während der Beobachtung tritt hier und da Stase in den Capillaren auf.

Flächen präparat: Fixe Zellen stark vermehrt, dazwischen Lymphocyten; polymorphkernige Leukocyten sehr vereinzelt. Außer der beschriebenen circumscripten Capillarneubildung (in Form von Mänteln um Venenstrecken) kommt auch diffuse vor. Spärliche große Tuberkel mit großem trüben zentralen Teil und lockerer zelliger peripherischer Zone, zahlreiche kleine und allerkleinste Tuberkel. Durch die größeren Tuberkel ziehen die (neugebildeten) Capillaren hindurch, während die kleineren meist capillarfrei sind.

Bacillen: In den größeren Knötchen mit trübem, zerfallenen Zentrum Bacillen sowohl im Innern wie in der peripherischen Zone. In den übrigen Tuberkeln meist reichliche Bacillen. Zwei Zellhäufchen, die sich genau wie Tuberkel verhalten und sich gut durchmustern lassen, ohne Bacillen.

6. Versuch: Beobachtung 7 Tage nach der Infektion.

Makroskopisch: Das Mesenterium der Duodenalschlinge etwas milchig getrübt. Entlang den größeæen Gefäßstämmohen sieht man bis fast stecknadelkopfgroße käsige Knötchen. 
Mikrosko pisch: Stark vermehrte Zellen. Schneller Strom in den Arterien, verlangsamter in den geschlängelten Venen und in den Capillaren, auch den neugebildeten. Capillarneubildung ziemlich beträchtlich, als Mantel von einer Breite bis zu 60 Intervallen. Es kommen auch große Strecken ohne neugebildete Capillaren vor. Außer zahlreichen Zellhäufchen von undeutlicher Begrenzung finden sich scharf begrenzte bisweilen mit trübem Zentrum; sie berühren Gefüße oder umgreifen solche. Die Tuberkel sind vielfach von Capillaren durchzogen, die von Venen oder von Capillaren des angrenzenden Fettgewebes ausgehen. Es kommen vereinzelte Tuberkel auch in capillarfreien Mesenterialgebieten vor.

Reaktionsversuch mit Sublimatlösung an einem von (neugebildeten) Capillaren durchzogenen, nicht ganz scharf begrenzten, zentral trüben Tuberkel, der eine Arterie $\left(1^{1 / 2}\right)$ und eine - fast gestreckte, schnell durchströmte - Vene (2) umgreift. Ohne daß sich die Weite der beiden Gefäße ändert, tritt nach 3 Minuten nahe dem Tuberkel in einer Capillare Stase, treten ferner 2 Ekchymosen auf. Nach 4 Minuten Stase in mehreren Capillaren. Nach 5 Minuten Arterie $1+$, die meisten Capillaren im Tuberkel mit Stase; viele kleine Ekchymosen. Nach 7 Minuten Stase in den Capillaren fast allgemein; Arterie 11/2. Nach 8 Minuten mißt die Arterie wieder $1+$, das Blut fließt nur noch in den größeren Gefäßen.

Flächen prä parat: Vermehrte fixe Zellen und Lymphocyten im Mesenterium. Capillarneubildung sehr beträchtlich, vorwiegend als Mantel um die Gefäße. Im Bereich dieses Capillarmantels auch zahlreiche polymorphkernige Zellen, ferner eine Anzahl undeutlich begrenzter Tuberkel, auch kleinster. Größere Tuberkel mit geringen Zerfallsveränderungen der Zellen im Zentrum und mit Capillaren (neugebildeten) in der peripherischen Zone.

Bacillen: Sehr zahlreiche Knötchen lassen Bacillen vermissen, andererseits finden sich Tuberkel, auch kleinste, mit einer großen Zahl von Bacillen. Ein großer länglicher Tuberkel mit geringen Zerfallsveränderungen im zentralen Teil enthält 6 Bacillenhäufchen; in seiner Nähe zwischen (vermehrten) Spindelzellen kleinere Bacillenhäufchen.

Sektion: Im Mesenterium des Blinddarmes ein hanfkorngroßes käsiges Knötchen.

7. Versuch: Beobachtung 7 Tage nach der Infektion.

Makroskopisch: Im Duodenalmesenterium ein über stecknadelkopfgroßer und zwei mohnkorngroße Tuberkel, davon einer im Fettgewebe.

Mikrosko pisch: Um die größeren Gefäße herum ein bis $2 \mathrm{~mm}$ breiter Saum eines dichten Netzes neugebildeter Capillaren. Nahe am Fettgewebe zwei kleine Zellhäufchen, durchzogen von Capillaren.

Flächen präparat: Vermehrung der fixen Zellen, besonders stark um die größeren Gefäße im Bereich des Mantels neugebildeter Capillaren. Spärliche Lymphocyten, ganz vereinzelte polymorphkernige Zellen. Das Netz neugebildeter Capillaren äußerst dicht. Mäßig zahlreiche größere bis kleinste Tuberkel, häufig scharf begrenzt. Die größeren z. T. mit Zerfallsveränderungen im Zentrum und mit leicht konzentrischer Anordnung der spindeligen Zellen im peripherischen Teil; in diesem kommen Capillaren vor, solche durchziehen auch die kleinsten Knötchen.

Bacillen: Tuberkel von gleichem Aussehen und verschiedener Größe enthalten teils Bacillen, teils sind sie frei von solchen. Nahe einem sehr kleinen Tuberkel mit wenigen verstreuten Bacillen ein Bacillenhäufchen in einer undeutlich ausgebildeten Riesenzelle. Im übrigen keine Bacillen außerhalb von TuberkeIn.

Sektion: Einzelne submiliare Tuberkel auf der Blinddarmserosa.

8. Versuch: Tod 8 Tage nach der Infektion.

Flächen prä parat: Die vermehrten fixen Zellen im Mesenterium sind stark deformiert, desgleichen ihre Kerne; in zahlreichen ist der Kern zu Chromatin- 
körnchen zerfallen. Die Neubildung von Capillaren ist weniger stark als beim vorigen Tier. Ziemlich zahlreiche Tuberkel von verschiedener Größe, scharf begrenzt, ohne Zerfallsveränderungen, außer daß die fixen Zellen, die sich in ihnen finden, wie außerhalb der Tuberkel deformiert sind und deformierte, z. T. in Chromatinkörnchen zerfallende Kerne aufweisen.

Bacillen: Im zentralen Teil großer dichter Tuberkel mit scharfer Begrenzung ein oder mehrere Bacillenhaufen, in der peripherischen Zone derselben sehr zahlreiche verstreute Bacillen; solche auch in der Nachbarschaft auf eine gewisse Entfernung, ohne daß Knötchenbildung angedeutet wäre. Auch in mittelgroßen Tuberkeln von scharfer Begrenzung kommen mehrere Bacillenhäufchen vor. Von den kleinsten, ebenfalls scharf begrenzten Tuberkeln enthalten die einen zahlreiche Bacillen, die anderen, bei gleichem Aussehen, keine. Es kommen kleinste Tuberkel mit zählbaren Zellen vor, die ein ganzes Bacillenhäufchen einschließen; einmal sieht ein solcher Tuberkel einer Riesenzelle ähnlich. Einmal wird auch ein Knötchen gefunden, das einen Fremdkörper (Gazepartikel) und zugleich zahlreiche Bacillen enthält. - In größerer Entfernung von Knötchen werden nur an einer Stelle mehrere Bacillen gefunden.

Sektion: Vereinzelte übermohnkorngroße käsige Knötchen auf einzelnen Darmschlingen.

9. Versuch: Beobachtung 8 Tage nach der Infektion, bei der das Mesenterium mehrmals mit einer Nadel durchstochen worden ist.

Makrosko pisch: Eine Anzahl eben sichtbarer Knötchen.

Mikrosko pisch: Es wird ein Tuberkel eingestellt nahe einer Arterie (1) und einer Vene (etwas über 1). Die Arterie ist leicht, die Vene stark verlangsamt durchströmt, beide stark geschlängelt. Von diesen Gefäßen geht ein Netz neugebildeter Capillaren aus, das sich im allgemeinen an die Grenzzone des Tuberkels hält, ihn aber auch mit einigen Maschen durchzieht.

Reaktionsversuch mit Sublimatlösung: Nach 2 Minuten Zunahme der Verlangsamung. Nach 4 Minuten hier und da Stase in Capillaren. Nach 7 Minuten ist die Stase vollständig. Die Arterie hat sich nicht verengt.

10. Versuch: Beobachtung 3 Wochen nach der Infektion.

Makroskopisch: Das Mesenterium der Duodenalschlinge sieht trüb aus; in einzelnen Sektoren kleine graue Knötchen.

Mikroskopisch: Sehr große Tuberkel sind im Zentrum trübe, zerfallen und enthalten in der lockeren peripherischen Zone Capillaren. Weit zahlreicher sind die kleinen Tuberkel; auch sie sind z. T. im Zentrum zerfallen und daselbst frei von Capillaren, während ihre zellreiche, scharf begrenzte peripherische Zone spärliche Capillaren enthält.

Reaktionsversuch mit Suprareninlösung: Nach 30 Sekunden Verschluß einer kleinen Arterie in der Nähe eines Tuberkels.

Das Tier stirbt; während des Sterbens treten rasch zahlreiche Stasecapillaren auf. Eine Verengerung der Arterien bleibt aus.

Flächen prä parat: Die fixen Zellen zahlreich (vermehrt); dazwischen ebenfalls ziemlich zahlreiche Lymphocyten und spärliche polymorphkernige Zellen. Capillarneubildung stark, aber bei weitem nicht maximal; wo keine Tuberkel vorhanden sind, relativ wenige Capillaren. Die Tuberkel bestehen vorwiegend aus einkernigen, epithelioiden Zellen; das oben beschriebene Verhalten der Capillaren zu bestätigen. - Bacillen finden sich nirgends.

Sektion:' Auf der Blinddarmserosa zahlreiche tautropfenartige Knötchen.

In der zweiten Versuchsreihe ist die die Tubrkelbacillen in feiner Verteilung enthaltende Flüssigkeit auf dás Duodenalmesenterium aufgeträufelt und daselbst zwei Minuten gelassen worden. 
Wir haben in dieser Reihe von Versuchen die Beobachtung bereits 3/4 Tage nach der Infektion begonnen und schon so bald den ersten Anfang von Capillarneubildung in Form zahlreicher spitz endigender, noch nicht zu Arkaden verbundener Sprossen festgestellt; desgleichen die Verlangsamung der Blutströmung in den geschlängelten Gefäßen und die starke Durchsetzung des mesenterialen Bindegewebes mit polymorphkernigen Leukocyten. Auch die kleinsten, bereits scharf begrenzten Zellhäufchen sind schon in geringer Zahl nachweisbar gewesen. Nach einem Tag, zu einem Zeitpunkt, den wir in der ersten Versuchsreihe ebenfalls noch nicht berücksichtigt haben, wurde einähnlicher Befund erhoben, doch fehlte noch die Capillarneubildung; die fixen Zellen fielen bereits durch Vergrößerung auf. Von den scharf begrenzten Knötchen waren die größeren im Zentrum bereits trüb, die daselbst befindlichen Zellen unkenntlich.

3 Tage nach der Infektion waren an einem Teil der fixen Zellen außer der Vergrößerung (amitotisch) vermehrte Kerne als Zeichen der im Gange befindlichen Hyperplasie nachzuweisen. Nunmehr handelte es sich bereits um ganze Netze von den Venen ausgehender neugebildeter Capillaren, die z. T. in die peripherische Zone der Tuberkel hineinreichten. Wie bisher waren diese aus vergrößerten und vermehrten fixen Zellen und aus polymorphkernigen Leukocyten, die auch außerhalb der Tuberkel das mesenteriale Bindegewebe durchsetzten, aufgebaut.

Nach 4 Tagen haben sich einige Abweichungen herausgestellt. Zwar war wie bisher die Strömung noch verlangsamt, aber die extravasierten weißen Blutkörperchen waren nur spärlich. Während wir bisher Stasecapillaren nicht zu erwähnen gehabt haben, sind solche nun im Netz der neugebildeten Capillaren reichlich vorhanden gewesen. Und wenn die Tuberkel bisher höchstens in ihrer peripherischen Zone Capillaren aufwiesen, sind nun neben capillarfreien solche vorhanden, die von Capillaren durchzogen sind.

Am 5. Tage ist ungefähr derselbe Befund erhoben worden; hier sind es die größeren Tuberkel gewesen, die von neugebildeten Capillaren durchzogen waren; in einem Teil derselben bestand Stase, die auch hier und da während der Beobachtung auftrat.

Vom 6. Versuch, 7 Tage nach der Infektion, ist hervorzuheben, daß die Strömung nur noch in den Venen und Capillaren, alten wie neugebildeten, verlangsamt, dagegen in den Arterien schnell war. Neben capillarfreien Tuberkeln fehlten von Capillaren durchzogene nicht. Im Gegensatz zu den beiden vorhergehenden wies das Präparat zahlreiche polymorphkernige Leukocyten im Bereich der sehr reichlich neugebildeten Capillaren auf. Die fixen Zellen waren stark vermehrt. Ein zweiter Versuch am selben Termin ergab im wesentlichen eine Bestätigung, doch waren hier die polymorphkernigen Leukocyten, wie auch die Lymphocyten, sehr spärlich. 
8 Tage nach der Infektion war die Capillameubildung geringer als zu früherer Zeit; außerdem waren die Zerfallsveränderungen an einem Teil der vermehrten fixen Zellen des mesenterialen Bindegewebes innerhalb und außerhalb der Tuberkel auffällig. Bei einem zweiten am 8. Tage nach der Infektion vorgenommenen Versuche ist ein Tuberkel genauer beobachtet worden, der im allgemeinen nur von Capillaren umgeben und außerdem von einigen durchzogen war.

3 Wochen nach der Infektion enthielten sowohl die großen, im Zentrum zerfallenen Tuberkel, als die kleinen, übrigens zum Teil ebenfalls zentral zerfallenen Tuberkel spärliche Capillaren nur im peripherischen Teil. Während des nach einer Berieselung mit Suprareninlösung eingetretenen Sterbens des Tieres trat.in zahlreichen Capillaren Stase auf.

Die Reaktion der alten Gefäße und Capillaren und der neugebildeten Capillaren haben wir wieder mit Suprarenin- oder Sublimatlösung geprüft. $3 / 4$ Tage nach der Infektion verengte sich zwar auf Suprarenin die Arterie, aber, im Gegensatz zum Verhalten einer normalen Arterie, nur auf ganz kurze Zeit, darauf stellte sich Erweiterung der Strombahn, Verlangsamung des Blutstromes und partielle Stase ein, bei rascher Wiederherstellung der Strömung nach dem Vertauschen der Suprarenin- mit Kochsalzlösung. Etwas mehr dem normalen Verhalten angenähert war die Reaktion 1 Tag nach der Infektion, hier verschloß sich die Arterie, aber verzögert und nachdem sie sich vorher statt gleichmäßig streckenweise, segmentär verengt hatte. Auch 3 Tage nach der Infektion war wenigstens bei dem einen der beiden vorgenommenen Reaktionsversuche als erste Wirkung der Suprareninberieselung die Arterie auf eine Strecke verengt, später und im anderen Versuche sofort trat Erweiterung und Verlangsamung mit Ausgang in Stase ein, und zwar erst nach Ubergang zur Berieselung mit Kochsalzlösung.

4 Tage nach der Infektion blieb die Verengerung auf Suprarenin aus, außer daß sich die Arterie stellenweise leicht einschnürte.

Am 7. und 8. Tage nach der Infektion ist das Verhalten gegen Sublimatlösung geprüft worden. Unter Ausbleiben der Verengerung stellte sich die Stase stark verfrüht ein. Dagegen verengte sich 3 Wochen nach der Infektion auf Suprareninlösung eine kleine Arterie nahe einem Tuberkel; im Tode blieb der sonst eintretende Verschluß der Arterien und Capillaren aus.

In bezug auf die Bacillen sei folgendes zusammengestellt. In den beiden ersten Versuchen haben wir Bacillen nur in Knötchen gefunden; ein Knötchen im 2. Versuch ist bacillenfrei gewesen. Im 3. Versuch sind Bacillenhäufchen aufgefallen, um die sich keine Knötchen gebildet hatten. In den Knötchen lagen die Bacillen zentral, handelte es sich um größere, auch im peripherischen Teil. In den Versuchen am 4. und 5. Tage haben 
sich Zellhäufchen von gleichem Aussehen wie mit Bacillen versehene gefunden, die keine Bacillen enthielten; die Bacillen lagen sowohl im zentralen als im peripherischen Teil der Tuberkel. Auch vom 6. und 7. Versuch - Beobachtung nach 7 Tagen - ist hervorzuheben, daß die Knötchen teils Bacillen enthielten, teils nicht; nur nahe mit Bacillen versehenen Tuberkeln kamen Bacillen auch im knötchenfreien mesenterialen Bindegewebe vor. Derselbe Befund ist am 8. Tage erhoben worden, während im letzten Versuch, 3 Wochen nach der Infektion, Bacillen überhaupt nicht nachweisbar gewesen sind. -

Ein vergleichender Rückblick auf die zweite Versuchsreihe lehrt, daß zwei Perioden der Wirkung des Eingriffes zu unterscheiden sind, von denen jede 5 Versuche umfaßt.

In dër ersten, von der 18. Stunde bis zum 5. Tage reichenden, haben wir eine schwere Alteration der Strombahnweite und Strömungsgeschwindigkeit im Sinne einer Erweiterung und Verlangsamung festgestellt, verbunden mit Extravasation von Leukocyten; gleichzeitig Neubildung von Capillaren, die vom 4. Tage ab auch in den Tuberkeln vertreten waren. Schon zu dieser Zeit sind die extravasierten polymorphkernigen Zellen spärlich, dagegen haben Stasecapillaren und Ekchymosen, vorher nicht beobachtet, am '4. und 5. Tage nicht gefehlt.

In der zweiten Periode, vom 7. Tager bis zum Ende der 3. Woche reichend, war die Strömung und Strombahnweite nur noch gering alteriert, insbesondere der Arterienstrom wieder schnell. Nur in dem einen der beiden am 7. Tage nach dem Eingriff vorgenommenen Versuche sind noch extravasierte weiße Blutkörperchen beobachtet worden. Stase und Ekchymosen waren nicht mehr festzustellen. Die Zahl der neugebildeten Capillaren hat in der 2. Periode abgenommen.

In bezug auf das Verhalten bei den. Reaktionen gegen künstliche Reize ist hervorzuheben, daß in den ersten Versuchen, die zu besonders früher Zeit angestellt worden sind, die Kontraktionsfähigkeit auf Suprarenin, wenn.auch in pathologischer. Form erhalten war, dasselbe in ab, nehmendem Maße ist aber auch noch vom 3. und 4. Tage zu berichten gewesen:- Erst nach 3 Wochen isst wieder eine kleine Arterie beobachtet. worden, die sich auf Suprarenin verengte; dazwischen am 7. und 8. Tage wurde' auf Sublimat die durch Ausbleiben der Verengerung und sehr verfrühten Eintritt der. Erweitherung und Stase charakterisierte stark abweichende Reaktion konstatiert.

Dritte Versuchsreihe (Injektion tuberkelbacillenhaltiger Flüssigkeit in die Bauchhöhle)

1. Versuch: Beobachtung 1 Tag nach der Injektion.

Flächen prä parat (Netz): Die fixen Zellen liegen in den gewöhnlichen $\mathrm{Ab}$ 6tänden, sind.nicht vermehrt. Das Netz ist nicht ganz gleichmäßig mit poly- 
morphkernigen Zellen durchsetzt, am dichtesten in der nächsten Umgebung der Gefäße. Ziemlich zahlreiche, im (gefärbten) Präparat z. T. mit unbewaffnetem Auge eben erkennbare, scharf begrenzte Häufchen polymorphkerniger Leukocyten, z. T. locker, 'z. T. so dicht, daß im Zentrum keine Einzelheiten mehr zu erkennen sind. Die Zellhäufchen stehen in keiner Beziehung zu den Gefäßen und sind wie ihre Umgebung eapillarfrei. Nirgends Capillarneubildung nachweisbar.

Bacillen: Sowohl die lockeren als die dichten, scharf begrenzten Zellhäufchen enthalten spärliche Bacillen. Außerhalb der Zellhäufchen ganz vereinzelte Bacillen.

2. Versuch: Beobachtung 2 Tage nach der Injektion.

I. Flächen präparat (Netz): Die fixen Zellen stellenweise abnorm groß, anscheinend vermehrt; einmal eine Mitose. Sehr starke, aber ungleichmäßige Durchsetzung mit polymorphkernigen Zellen; außerdem kommen teils undeutlich, teils scharf begrenzte Zellhäufchen vor, einzelne mit (neugebildeten) Capillaren an der Peripherie. Im ganzen sind zahlreiche neugebildete Capillaren vorhanden.

Bacillen: Die Zellhäufchen sind vorwiegend bacillenfrei; im diffusen Infiltrat ganz spärliche Bacillen.

II. Flächenpräparat (Dünndarmmesenterium): Infiltration mit poly-morphkernigen Zellen, aber weit geringer als im Netz, vorwiegend circumvasculär. Stellenweise Andeutung von Knötchenbildung; ein scharf begrenzter, schon mit unbewaffnetem Auge sichtbarer Tuberkel. Ziemlich starke Capillarneubildung.

Bacillen: Nur in dem distinkten Tuberkel Bacillen.

3. Versuch:'Beobachtung 2 Tage nach der Injektion.

Mikroskopisch (Mesenterium der Duodenalschlinge): Langsame Strömung in erweiterter Strombahn. Vermehrte Zellen. Einige ältere Ekchymosen.

Reaktionsversuch mit Suprarenin: Nach 30 Sekunden Venenstrom stärker verlangsamt. Nach 45 Sekunden Arterie (Ausgangsmaß 2) auf 1 verengt, Venenstrom stärker verlangsamt. Nach $1 \frac{1 / 4}{4}$ Minuten Arterie verschlossen, Venenblut steht still.

FIächenpräparat (Duodenalmesenterium): An einzelnen Stellen neugebildete Capillaren. Spärliche Häufchen polymorphkerniger Leukocyten in der nächsten Nähe von Gefäßen.

4. Versuch: Beobachtung 4 Tage nach der Injektion.

Sektionsbef und: In der Blinddarmserosa und im Netz mehrere bis hirsekorngrỏße trübe Knötchen. In der Dünndarmserosa einige eben sichtbare graue Knötchen. '

I. Flächen präparat (Netz): Die fixen Zellen vermehrt. Sehr dichte Durchsetzung 'mit Lymphocyten, besonders als Mantel um die Gefäße. Polymorphkernige Zellen ganz spärlich. Scharf umschriebene Häufchen von Lymphocyten ohne Capillaren. Nirgends sichere Capillarsprossen.

Bacillen: Ganz vereinzelte Bacillen außerhalb der Zellhaufen.

II. Fläcḥen präparat (Dünndarmmesenterium): Die fixen Zellen allgemein vermehrt. Die makroskopisch sichtbar gewesenen Knötchen bestehen aus Lymphocyten; ebenso sind allerkleinste Zellhäufchen zusammengesetzt. Capillarneubildung, stellenwejse gering, an andèren Stellen stärker. In den Knötchen keine Capillaren.

Bacillen: Die größeren Knötchen enthalten mehr oder weniger zahlreiche Bacillẹn; die mikroskopisch kleinen Knötchen teils bacillenfrei, teils mit Bacillen im Innern odẹr am Rạde.

5. Versuch: Beobachtung 7 Tage nach der Injektion.

Sektionsergebnis: Im Netz ein über hirsekorngroßes und ein kleineres käsiges Knötchen.

I. Flächen präparat (Netz): Durchsetzung mit nicht sehr zahlreichen Lymphocyten, spärlicheren als beim vorigen Tier. Wenig polymorphkernige 
Zellen im Gewebe. Zahlreiche sowohl diffus begrenzte als scharf abgesetzte Zellhäufchen. Keine deutliche Capillarneubildung nachweisbar. Die Zellhäufchen capillarfrei.

II. Flächen prä parat (Dünndarmmesenterium): Fixe Zellen vermehrt, eine Mitose. Keine polymorphkernigen Zellen im Gewebe. Ein kleines scharf begrenztes Zellhäufchen, bestehend aus Zellen, die teils wie Lymphocyten, teils wie fixe Zellen aussehen. Nicht sehr starke Capillarneubildung.

Bacillen: Nicht nachweisbar.

6. Versuch: Beobachtung 11 Tage nach der Injektion.

I. Flächen präparat (Netz): Starke Lymphocytenansammlung in der Nähe der Gefäßchen und im Bereich der stellenweise zahlreichen neugebildeten Capillaren. Auch scharf begrenzte Lymphocytenhäufchen.

Bacillen: Spärlich in einzelnen dieser Knötchen.

II. Flächen prä parat (Blinddarmmesenterium): Allgemeine Vermehrung der fixen Zellen und Lymphocyteninfiltration; äußerst spärliche polymorphkernige Leukocyten. An den Gefäßchen und in ihrer Umgebung Lymphocytenhäufchen. Ein makroskopisch sichtbar gewesenes knötchenähnliches Gebilde ist im Zentrum zerfallen und besteht an der Peripherie aus Lymphocyten und großen Zellen. Ziemlich starke Capillarneubildung.

Bacillen: Das größere Knötchen enthält zahlreiche Bacillen. Die kleineren aus Lymphocyten bestehenden frei davon.

7. Versuch: Beobachtung 14 Tage nach der Injektion.

Mikrosko pisch: Es werden 3 Tuberkel näher untersucht. Der erste, rundlich, scharf begrenzt, im Innern dicht, an der Peripherie locker, liegt nahe einem venösen Gefäßchen mit langsamem Strom; die Vene ist geschlängelt. Von der begleitenden Arterie geht ein Netz neugebildeter Capillaren aus, von denen eine enge am Rande des Tuberkels, der sonst capillarfrei ist und in capillarfreiem Gebiet liegt, vorbeizieht.

Ein zweiter kleinerer, ebenfalls scharf abgesetzter Tuberkel wird in seiner peripherischen Zone von einem kleinen geschlängelten Venenast durchsetzt und von einer engen Capillare berührt, deren Blut in Stase ist; in der Umgebung des Tuberkels einzelne ebenfalls enge Capillaren mit Stase. Die Capillaren gehen von der Vene aus.

Ein dritter sehr kleiner Tuberkel liegt in ganz capillarfreiem Gebiet; erst in einiger Entfernung eine große Vene mit adventitiellen Capillaren, die, wie Bindegewebszellen mit kleinen Fetttropfen anzeigen, ursprünglich Fettgewebscapillaren gewesen sind. Eine enge Capillare reicht nahe an den Tuberkel heran.

Auch wo keine Tuberkel sind, findet man an mehreren Stellen neugebildete Capillaren, auch engste Capillarsprossen.

Sektionsbefund: Zahlreiche Tuberkel im Mesenterium des Blinddarmes und im Netz, wenige Tuberkel im Mesenterium des Dünndarmes und im Peritoneum des Zwerchfelles. Einzelne größere käsige Knoten in der Serosa einzelner Darmschlingen.

Flächen präparat des Duodenalmesenteriums: Im ganzen Mesenterium vermehrte fixe Zellen. Infiltratzellen fehlen im allgemeinen; nur an einer Stelle mit sehr zahlreichen Tuberkeln und neugebildeten Capillaren ein diffuses Infiltrat von Lymphocyten. - Die Zahl der Tuberkel schwankt an den verschiedenen Stellen sehr; die Tuberkel sind klein, scharf begrenzt; die Tuberkelzellen sind einkernig; selten im Zentrum leichte Zerfallsveränderungen. Capillarneubildung im ganzen erheblich. Man sieht Gefäßchen gestreckt durch Tuberkel hindurchziehen. Am Rande einer Anzahl von Tuberkeln zahlreiche sehr enge Capillaren. Manche Tuberkel liegen ganz in capillar- und gefäßfreiem Gebiet.

Bacillen: Nicht nachweisbar. 
8. Versuch: Beobachtung 15 Tage nach der Injektion.

Makroskopisch: Im Mesenterium der Duodenalschlinge einige graue Knötchen.

Mikroskopisch: Eingestellt eines dieser Knötchen - ein großer ziemlich scharf abgesetzter Zellhaufen, durchzogen von Capillaren; in nächster Nähe eine Arterie (2) und eine geschlängelte Vene. Überall flotte Strömung.

Reaktionsversuch an dieser Stelle mit Suprareninlösung: Nach 2 und 3 Minuten Venenstrom leicht verlangsamt, Arterie und Capillaren nicht verengt.

Nunmehr Berieselung mit Kochsalzlösung: Nach 20 Sekunden starke Verlangsamung des Blutstromes, nach 50 Sekunden Stillstand, ohne daß sich die Weite geändert hätte.

Flächen präparat (Duodenalmesenterium): Stellenweise in mäßiger Ausdehnung neugebildete Capillaren. Zahlreiche meist scharf begrenzte Tuberkel, die meisten im gefäß- und capillarfreien Teil des Mesenteriums.

Sektionsergebnis: Kein ErguB, nirgends Belag. Ưberall sehr zahlreiche feinste bis mohnkorngroße Knötchen, besonders auch in dem dadurch verdickten Netz. - Abgesehen vom Bauchfell keine Knötchen im Körper sichtbar.

9. Versuch: Beobachtung 16 Tage nach der Injektion.

Sektionsbefund: Einzelne erbsengroße käsige Knoten in der Darm- und Bauchwandserosa. Daselbst und in der Serosa des Zwerchfells, der Leber und der Milz kleinste Tuberkel.

I. Flächen prä parat des Duodenalmesenteriums: Die fixen Zellen vermehrt. Äußerst zahlreiche, meist kleine bis kleinste scharf begrenzte Tuberkel; sie bestehen aus einkernigen Zellen, deren Kerne stark geschrumpft aussehen. Sowohl in den Knötchen als außerhalb derselben viele Häufchen von Chromatinkörnchen. Das Mesenterium ist durchzogen von einem ziemlich weitmaschigen Capillarnetz; Capillaren desselben ziehen oft durch Tuberkel hindurch. Auch entfernt von Capillaren kommen Tuberkel vor.

Bacillen: Nicht nachweisbar.

II. Flächen prä parat des Mesenteriums einer Dünndarmschlinge: Ungefähr ebenso zahlreiche, meist etwas größere, aus wohlerhaltenen epithelioiden Zellen und Lymphocyten bestehende Tuberkel. Die Häufchen von Chromatinkörnchen fehlen. Die (neugebildeten) Capillaren weit weniger zahlreich als im Mesenterium der Duodenalschlinge. Durch viele Knötchen ziehen enge Capillaren.

Bacillen: Einzelne in weiten Abständen fast in jedem Tuberkel.

10. Versuch: Beobachtung 17 Tage nach der Injektion.

Mikroskopisch: Im allgemeinen zahlreiche, scharf begrenzte, ziemlich gleichgroße Tuberkel, z. T. miteinander zusammenhängend; eine ausgesprochene Trübung des zentralen Teiles fällt nicht auf. Beträchtliche Neubildung von Capillaren, zahlreiche davon sehr eng, die übrigen sehr weit und langsam durchströmt. Sehr geringe Zahl von Stase-Capillaren, darunter solche mit entfärbtem Inhalt. Sehr vereinzelte Ekchymosen. Die neugebildeten Capillaren durchziehen nicht das ganze Mesenterium, sie überschreiten nicht eine bestimmte Entfernung von den Gefäßen, aus denen sie hervorgehen.

Die Tuberkel liegen teils im Bereich des Capillarnetzes, teils außerhalb desselben. Fin Teil der Tuberkel enthält in seiner peripherischen, etwas lockeren Zone Capillaren, andere Tuberkel nur in einem Teil der peripherischen Zone; wieder andere grenzen nur an Gefäßchen oder Capillaren an.

Nach einer Beobachtung von 10 Minuten Dauer stirbt das Tier. Arterien, Venen und Capillaren bleiben gefüllt, während die größeren Arterienäste am Darm eng werden.

Sektionsbefund: Das ganze Mesenterium und die ganze Darmserosa übersät mit feinsten grauen Knötchen, desgleichen das Netz. Úberhirsekorngroße 
Knötchen in der Serosa des Zwerchfelles. Erbsengroße käsige flache Tuberkel vereinzelt in der Serosa der Bauchwand, des Dickdarmes und des Beckens.

Fläch en präparat des Mesenteriums der Duodenalschlinge: Die fixen Zellen vermehrt, spärlich Lymphocyten. Stellenweise Gefäßneubildung, große Strecken aber capillarfrei. Sehr zahlreiche oft verschmolzene Tuberkel, mittelgroße bis kleinste. Sie bestehen aus wohlerhaltenen einkernigen Zellen und sind oft durchzogen von gestreckten Gefäßchen. Die größeren enthalten oft enge, leere Capillaren. In der Nachbarschaft dicht angehäufter Tuberkel Lymphocyten.

Bacillen: In sämtlichen Knötchen in geringer Zahl.

11. Versuch: 20 Tage nach der Injektion.

Mikroskopisch (Stelle, die bereits 6 Tage nach der Injektion untersucht worden war und nichts Auffälliges gezeigt hatte; keine Verwachsung der DuodenalSchlinge): Ein diffuses Zellinfiltrat ist nicht vorhanden. Sehr zahlreiche kleinere und kleinste, scharf abgesetzte Zellhäufchen, ferner größere, mehr diffus begrenzte,' die den Eindruck erwecken, aus kleineren hervorgegangen zu sein. Keine trüben Stellen in den Tuberkeln. Sehr ausgedehnte Capillarneubildung im Mesenterium; die von den Gefäßchen, von denen sie ihren Ursprung nehmen, am entferntesten gelegenen Capillaren sind leer oder mit stillestehendem Blut gefüllt, die übrigen durchiströmt, doch kommen auch anter ihnen Stasecapillaren vor. Vereinzelte Ekchymosen; während der Beobachtung nehmen die Stasecapillaren und Ekchymosen an Zahl etwas zu. Viele Tuberkel enthalten Capillaren sowohl am Rande als im Innern; in einigen sind Stasecapillaren und kleinste Ekchymosen vertreten. Durch größere diffuse Tuberkel ziehen auch Arterien oder Venen hindurch.

Mikroskopische Beobachtung des Mesenteriums einer Dünndarmschlinge der gegenüberliegenden Körperseite beim lebenden Tier. Fixe Zellen etwas vermehrt. Vereinzelte kleinere und größere Tuberkel. Capillarneubildung geringer als im Duodenalmesenterium, auch in den Tuberkeln; doch kommen solche mit Capillaren im Innern, auch Stasecapillaren, vor. Ganz vereinzelt sind die Stellen mit Capillarneubildung, wo Tuberkel fehlen.

Sektionsbefund: Zahlreiche submiliare Tuberkel im Mesenterium und in der Serosa des Blinddarmes. Einzelne Tuberkel derselben Größe im Mesenterium des Dünndarmes, im Netz und in der Zwerchfellserosa. Ganz spärliche kleinerbsengroße käsige Knoten im parietalen Peritoneum.

12. Versuch: 20 Tage nach der Injektion. 14 Tage nach derselben war bereits eine mikroskopische Untersuchung vorgenommen worden, die nichts Auffälliges ergeben hatte.

Mikrosko pisch: Zahlreiche, scharf begrenzte Zellhaufen von verschiedener Gräße mit Capillaren; im Inneren der größeren, im Zentrum etwas trüben Zellhaufen enge, nicht durchströmte Capillaren. Im Mesenterium einer Dünndarmschlinge der gegenüberliegenden Körperseite ein scharf begrenzter Tuberkel mit einer Capillare in der Randzone. In der Nachbarschaft vereinzelte neugebildete Capillaren.

Sektionsbefund: Im wesentlichen wie beim vorigen Tier.

13. Versuch: Beobachtung 22 Tage nach der Injektion.

Mikroskopisch: Zahlreiche Tuberkel, stellenweise außerordentlich beträchtliche Capillarneubildung. Flotte Strömung.

Reaktionsversuch mit Suprareninlösung: Nach 2 Minuten allgemeine Stase, ohne vorausgegangene Verengerung.

In der dritten Versuchsreihe, bei der die Bacillen, in physiologischer Kochsalzlösung fein verteilt, in die Bauchhöhle injiziert worden sind, 
haben wir außer dem Mesenterium des Duodenums und anderer Darmschlingen das Netz berücksichtigt.

Am 1. und 2. Tage nach der Injektion war das Bauchfell mit polymorphkernigen Zellen durchsetzt, die stellenweise Häufchen bildeten. Während am 1. Tage an den fixen Zellen nichts auffiel, waren sie am zweiten vergrößert und wohl schon vermehrt; im Gegensatz zum 1. Tage waren am 2. bereits neugebildete Capillaren, auch an der Peripherie der Zellhäufchen, nachweisbar. 4 Tage nach der Infektion standen die Lymphocyten als Infiltrationszellen und Komponenten von - capillarfreien - Knötchen im Vordergrunde vor den polymorphkernigen Leukocyten; der Umfang der Capillarneubildung wechselte an den verschiedenen Stellen.

Am 7.Tag hatten die Infiltratzellen, vorwiegend Lymphocyten, ab-, die capillarfreien Tuberkel zugenommen. Im Dünndarmmesenterium gelang der Nachweis sowohl der Vermehrung der fixen Zellen als der Capillaren. Ähnlich. war der Befund am 11. Tage.

14 Tage nach der Injektion wurden die Tuberkel wie vorher capillarfrei angetroffen, nur erstreckten sich neugebildete Capillaren an einen Teil derselben dicht heran oder umgaben Tuberkel ringsum. In diesem Versuch sind uns zum erstenmal in dieser Reihe Capillaren mit Stase in geringer Zahl entgegengetreten. Infiltratzellen fehlten zu dieser Zeit, mit Ausnahme einer tuberkelreichen Stelle mit zahlreichen Lymphocyten.

Enger ist die Beziehung zwischen Tuberkeln und Capillaren am16.Tage nach der Injektion gewesen; von den neugebildeten Capillaren, die jetzt ein nicht mehr enges, sondern weites Netz bildeten, zogen Abschnitte durch Tuberkel hindurch. Wie früher waren die fixen Zellen vermehrt; an den einkernigen Zellen des Bauchfells fiel das geschrumpfte Aussehen der Kerne auf. Chromatinkörnchen innerhalb und außerhalb von Tuberkeln waren auf Zerfall von Infiltratzellen, und zwar offenbar.polymorphkernigen, zurückzuführen.

17 Tage nach der Injektion waren sowohl capillarfreie als zum Teil oder ganz mit Capillaren versehene Tuberkel vorhanden, bei sehr großer Zahl der Tuberkel und bei zumeist starker Capillarneubildung. Stasecapillaren und Ekchymosen wurden spärlich angetroffen. Die fixen Zellen vermehrt, die Lymphocyten spärlich. Ähnlich war der Befund am 20. Tage. In beiden Versuchen waren zahlreiche Tuberkel zweifellos miteinander verschmolzen. Der zweite am 20. Tage angestellte Versuch hat diesen Befund bestätigt.

Die mit Suprarenin angestellten Reaktionsversuche haben am 2. Tage starke Verspätung, am 15. und 22. Tage Ausbleiben des Verschlusses und Stase ergeben, und zwar am 15. Tage Stase erst nach Úbergang zur Kochsalzberieselung; am 22. Tage noch während der Suprarenineinwirkung. 
Ein Vergleich der Netzveränderungen mit denen des Darmmesenteriums ergibt keine durchgreifenden Unterschiede. Die Frage, ob und in welchem Umfange Capillaren neugebildet waren, war an den Netzpräparaten schwieriger und unsicherer zu beurteilen, als am Darmmesenterium, weil dieses in großer Ausdehnung capillarfrei, jenes mit seinem reichlichen Fettgewebe weit ausgedehnter mit Gefäßchen und Capillaren versehen ist; wir haben uns auf die Mitteilung sicherer Beobachtungen beschränkt.

Für die ganze Versuchsreihe ist noch das seltene Vorkommen zentral getrübter, zerfallener Tuberkel hervorzuheben.

Die Bacillen waren bereits in den am 1. Tag nach der Infektion festgestellten Knötchen nachweisbar, außerhalb derselben aber sehr spärlich. Am 2. Tage verhielt es sich umgekehrt; wir konnten in den Knötchen - mit einer Ausnahme - keine Bacillen finden, wohl aber außerhalb jener. Am 4. Tage waren sowohl bacillenfreie als bacillenhaltige Knötchen vorhanden, während es uns am 7. und 14. Tage nicht gelungen ist, Bacillen aufzufinden. Auffällig war der Gegensatz am 16. Tage; hier fanden wir in den Tuberkeln des Duodenalmesenteriums keine, in denen des Mesenteriums einer anderen Dünndarmschlinge fast ausnahmslos Bacillen. Am 17. Tage enthielten alle untersuchten Tuberkel Bacillen. -

Es erübrigt sich, nach der Mitteilung dieser Beobachtungen eine Zusammenfassung unter Hervorheben des Wichtigsten zu geben, da in den Grundzügen Übereinstimmung mit dem in den beiden ersten Versuchsreihen Festgestellten besteht. Es sei nur hervorgehoben, da $B$ auch hier einem Zeitraum mit stärkerer Neubildung von Capillaren und Extravasation weißer Blutkörperchen eine Periode gefolgt ist, in der die Capillaren an Zahl verringert waren und die extravasierten Zellen gefehlt haben. Auffällig ist aber die sehr große Menge neugebildeter Capillaren in einem der am 20. Tage und in dem am 22. Tage angestellten Versuche gewesen; dabei haben Infiltratzellen gefehlt. Es wären weitere Versuche notwendig gewesen, um zu ermitteln, ob es sich hier um etwas Gesetzmäßiges, etwa um einen Teilakt der Entstehung einer neuen Serie von Tuberkeln, gehandelt hat, und ob in einem solchen Falle die Extravasation von Leukocyten ausbleibt.

In den drei Versuchsreihen hat es sich dem Wesen nach um übereinstimmende pathologische Vorgänge gehandelt.

Die erste Wirkung des Eingriffes ist eine akute Entzündung, hierunter verstehen wir einen bestimmten Typus der Strombahnerweiterung und Strömungsverlangsamung, der mit Extravasation weißer Blutkörperchen einhergeht, unter denen bald die polymorphkernigen und multinucleären, bald die Lymphocyten überwiegen. Dieser Typus geht stellen- 
weise über in einen anderen, charakterisiert durch verstärkte Verlangsamung und Stillstand des Blutes, die mit Extravasation roter Blutkörperchen verbunden sind. Gleichzeitig mit dieser Alteration der Strombahnweite und Blutströmung kommt eine Neubildung von Capillaren und eine Vermehrung der fixen Zellen zustande.

Die meisten dieser Vorgänge hören von einer gewissen Zeit ab auf. Die Strombahnweite und Strömungsgeschwindigkeit nähern sich für das Auge wieder der Norm an, die extravasierten Zellen verschwinden und eine weitere Extravasation weißer und roter Blutkörperchen unterbleibt; die Capillarneubildung wird abgebrochen und ein Teil der neugebildeten Capillaren verschwindet.

In beiden Stadien, dem ersten akuten und dem sich daran anschlieBenden zweiten Stadium, sind in größerer oder geringerer Zahl Zellhäufchen, Tuberkel, vorhanden, bestehend aus den jeweils vorhandenen Zellen - vermehrten Gewebs- und weißen Blutzellen —, bald mit Capillaren versehen, bald ohne solche.

Während des ganzen Prozesses in der von uns berücksichtigten Zeitdauer verhalten sich die Gefäße und Capillaren, alte wie neugebildete, gegen künstliche Reize anders wie normale, und zwar in einem mit der Zeit abnehmenden Grade.

Wenn dies die allgemeinen - später zu erläuternden - Vorgänge in den 3 Versuchsreihen sind, so ergibt der Vergleich zwischen ihnen weiter, daß die In- und Extensität jener Vorgänge verschieden ist. Zum Beweise sei angeführt, daß das akute Stadium mit den starken Abweichungen von der Norm in der ersten Versuchsreihe bis zum 11., in der zweiten nur bis zum 5. Tage gedauert hat, da $B$ die histiologisch nachweisbaren Veränderungen in der ersten Reihe stärker gewesen sind als in der zweiten und gar dritten, und daß die Abweichungen in der Reaktion der Gefäße und Capillaren gegenüber den experimentellen Reizen in der 1. Versuchsreihe beträchtlicher gewesen sind als in der zweiten.

Unter diesen Umständen waren Kontrollversuche geboten, in denen dieselben Eingriffe vorgenommen worden sind, mit dem Unterschiede, daß keine Bacillen eingeführt wurden; in einigen Versuchen haben wir, um die Mitwirkung feinster, chemisch indifferenter Fremdkörper kennen zu lernen, Tusche der Kochsalzlösung beigegeben. Wir berichten über diese Versuche in abgekürzter Form auf Grund ausführlicher Protokolle.

\section{Kontrollversuche.}

I. Wirkung der A ufpinselung von steriler Kochsalzlösung auf das Duodenalmesenterium während $1 / 2$ Minute. Beobachtung nach 6 Tagen.

In bezug auf die Zellinfiltration, Capillarneubildung, Befund von Stasecapillaren und Ekchymosen im wesentlichen derselbe Befund, wie zur selben Zeit in einem Mesenterium, das mit bacillenhaltiger Kochsalzlösung ebensolange be- 
pinselt worden war. Nur fehlen Knötchen. Auf Berieselung mit Sublimatlösung bleibt Verengerung der Arterie aus und die Stase tritt verfrüht ein.

Flächen präparat: Starke Vermehrung der fixen Zellen, Lymphocyteninfiltration, Capillarneubildung. Hier und da tubèrkelähnliche Zellhäufchen.

II. Wirkung der Benetzung des Duodenalmesenteriums während zwei Minuten mit steriler Kochsalzlösung.

1. Beobachtung nach $3 / 4$ Tagen.

Während der Berieselung mit Suprareninlösung bleibt die Verengerung der Arterie und Capillaren aus und die Strömung verlangsamt sich überall stark. Unter Berieselung mit Kochsalzlösung verengt sich 'nach einigen Minuten die Arterie stark, fast bis zum Verschluß.

Flächen prä parat: Anhäufung von polymorphkernigen Zellen und Lymphocyten um einen Teil der Gefäßchen. Keine Capillarneubildung.

2. Beobachtung nach 5 Tagen.

Reaktionsversuch mit Suprareninlösung: Nach 1 Minute leichte Verengerung der Arterie. Zunehmen der Verlangsamung des Blutstromes in den folgenden Minuten. Wechselndes Verhalten der Geschwindigkeit bei weiterer Strombahn unter minutenlanger Berieselung mit Kochsalzlösung.

Flächen präparat: An einzelnen Stellen neugebildete Capillaren in wechselndem Umfange. Daselbst Anhäufung vòn polymorphkernigen Leukocyten und von Lymphocyten. Im übrigen Mesenterium fixe Zellen vergrößert, ganz vereinzelte Lymphocyten.

3. Beobachtung nach 6 Tagen.

Flächenpräparat: Starke allgemeine Vermehrung der fixen Zellon, sehr vereinzelte polymorphkernige Zellen. An mehreren Stellen Häufchen einkerniger Zellen, die sich in keiner Weise von Tuberkeln unterscheiden. Sie sind capillarfrei, liegen aber im Gebiet neugebildeter Capillaren; die sehr zahlreich, als Mantel um Gefäßohen, aufgetreten sind. Zahlreiche Ekchymosen.

4. Beobachtung nach 4. Wochen.

Flächenpräparat: Die fixen Zellen gleichmäßig stark vermehrt. Dazwischen Lymphocyten. An einer Stelle ein kleines tuberkelähnliches Zellhäufchen aus vermehrten fixen Zellen. Beträchtliche Capillameubildung in Form eines weitmaschigen Netzes.

III. Wirkung der Injektion von $20 \mathrm{ccm}$ steriler körperwarmer Kochsalzlösung in die Bauchhöhle.

1. Beobachtung nach 2 Tagen: Im Mesenterium des Duodenums hier und da einige Leukocyten.

Reaktionsversuch mit Súprareninlösung: Die eine der eingestellten Arterien verschließt sich nach 15 Sekunden, diè andere ein wenig später.

2. Beobachtung nach 3 Tagen: Nichts auffallendes.

IV. Wirkung der Benetzung des Duodenalmesenteriums mit Tusche. aufschwemmung in Kochsalzlösung während zwei Minuten.

1. Beobachtung naćch 2 Tagen.

Flächenpräparat: Stellenweise starke Durchsetzung mit polymorphkernigen Zellen und Lymphocyten; häufig Zerfallsveränderungen an den Kernen der polymorphkernigen. Capillarneubildung gering. Wenig Tusche in feinsten Partikeln nur stellenweise. Wo sie etwas reichlicher ist, finden sich tuberkelähnliche Häufchen aus ein- und polymorphkernigen Zellen. An einer Stelle, um eine Vene herum, drei solcher Knötchen. Die Knötchen capillarfrei. Die Tusche liegt nicht in Zellen.

2. Beobachtung nach.4 Tagen.

Flächenpräparat: Starke Durchsetzung mit Lymphocyten und geringe mit polymorphkernigen Zellen. Starke Capillarneubildung. Die - ziemlich reich- 
liche - Tusche liegt z. T. in tuberkelähnlichen Zellhäufchen, und zwar in Zellen; die Zellhäufchen capillarfrei. Tuschehaltige Zellen auch im diffusen Zellinfiltrat. Es kommen auch Tuscheklümpchen vor mit sehr wenig Zellen in der nächsten Umgebung.

3. Beobachtung nach 5 Tagen, am lebenden Tier.:

Um die Gefäßchen starke Capillarneubildung und Ansammlung von Leukocyten. Ein scharf sich absetzendes Zellhäufchen mit Tusche weist Capillaren in der peripherischen Zone auf.

Reaktionsversuch mit Suprareninlösung: Nach 1 Minute Arterie etwas erweitert. Nach 2 Minuten Arterie wieder von der ursprünglichen Weite. Nach 5 Minuten fast vollkommene Stase, die sich während der nun folgenden Berieselung mit Kochsalzlösung hält.

Flächen präparat: Starke Vermehrung der fixen Zellen und Infiltration mit Lymphocyten. Starke Capillarneubildung. Nicht sehr scharf abgesetzte Häufchen einkerniger Zellen mit Tusche.

4. Beobachtung nach 7 Tagen.

Flächen prä parat: Vermehrung der fixen Zellen. Infiltration mit Lymphocyten. Capillarneubildung. Vereinzelte scharf begrenzte Zellhaufen ohne Capillaren mit teils spärlicher, teils etwas reichlicherer Tusche in feiner Verteilung. Ferner locker gebaute größere tuschehaltige Zellhaufen ohne scharfe Begrenzung, schließlich Tuschepartikelchen ohne Zellansammlung in der Umgebung.

5. Beobachtung nach 11 Tagen.

Flächen präparat: Fixe Zellen leicht vermehrt. Sehr wenige Lymphocyten. Capillarneubildung, als Mantel um Gefäßchen, geringer als beim vorigen Tier. Die Tusche sehr spärlich, in undeutlich begrenzten Zellhaufen mit Capillaren, in feinster Verteilung in Zellen gelegen. Größere Tuschepartikel in lockerer Gruppierung ohne auffällige Zellanhäufung in der Umgebung.

Die mitgeteilten Versuche sind nicht zahlreich genug, um einen genauen Vergleich in bezug auf die zeitlichen und quantitativen Eigentümlichkeiten der Befunde zu ermöglichen, es genügt aber vollständig der von ihnen erbrachte Beweis, daß sowohl nach Aufpinselung von Kochsalzlösung auf das Duodenalmesenterium wie nach Benetzung dieses in der früher genau beschriebenen, mit mechanischer Läsion, mit Feuchtigkeitsund Temperaturänderung einhergehenden Weise sich im wesentlichen derselbe Prozeß einstellt, als wenn die angewandten Flüssigkeiten Tuberkelbacillen enthalten hätten: haben wir doch das abnorme Verhalten der Strombahnweite und Strömungsgeschwindigkeit, die veränderte Reaktion der Gefäße und Capillaren, die Extravasation weißer Blutkörperchen, Stasecapillaren und Ekchymosen, Vermehrung der Capillaren und fixen Zellen beobachtet, ja sogar mit Tuberkeln histiologisch im wesentlichen übereinstimmende Knötchen haben nicht gefehlt, besonders nicht in den Versuchen mit Tuscheaufschwemmung. Dagegen hat sich, wie $\mathrm{zu}$ erwarten gewesen, die Injektion von physiologischer Kochsalzlösung in die Bauchhöhle als so gut wie einflußlos erwiesen.

Der Ausfall der Kontrollversuche könnte somit zu dem Schluß Veranlassung geben, daß wir in den unter Aufpinselung von und Benetzung mit bacillenhaltiger Flüssigkeit angestellten Versuchen lediglich die 
Wirkung des Infizierverfahrens, der Pinselung und Benetzung, vor uns gehabt hätten, und daß die Rolle der Tuberkelbacillen damit erschöpft gewesen sei, daß sie die Entstehung weit zahlreicherer Knötchen hervorgerufen hätten, als sonst beobachtet wurden. Daß dem nicht so ist, ergibt die Berücksichtigung der Injektionsversuche, bei denen wir die reine Wirkung der Tuberkelbacillen vor uns gehabt haben.

Die Protokolle über die Injektionsversuche zeigen, daß wir in diesen im wesentlichen dieselben, nur anfangs weniger intensiv ausgebildeten Befunde festgestellt haben, wie in den beiden anderen Versuchsreihen mit einer gröberen Art der Infektion. Es kommt hinzu, daß auch diejenigen Veränderungen, die sich in großer Entfernung von der mit Bacillenaufschwemmung bepinselten oder berieselten Fläche im Bereiche aus der Bauchhöhlenflüssigkeit implantierter Bacillen ausgebildet hatten, in allen Einzelheiten mit den Veränderungen in den unter akzessorischen Läsionen infizierten Teilen übereingestimmt haben. Es bedürfte weiterer Versuche, um zu einem Urteil zu gelangen, ob die verschiedenen von uns benutzten Infizierverfahren irgendwie einen Einfluß auf die Entwicklung der tuberkulösen Veränderungen ausüben. Uns ist bei einem Vergleich der drei Reihen nichts derartiges aufgefallen, abgesehen von dem eben erwähnten ruhigeren Beginn der Vorgänge bei der Infektion durch Injektion, dem lediglich eine quantitative Bedeutung zukommt.

Unter Verwertung unseres gesamten Beobachtungsmaterials ergeben sich somit folgende Sätze. Werden Tuberkelbacillen a uf die denkbar schonendste Weise in den Peritonealraum gebracht, so bewirken sie im Bauchfell da, wo sie haften, und da, wo sie nicht nachweisbar sind, Alteration der Strombahnweite (Erweiterung) und der Strömungsgeschwindigkeit (Verlangsamung), die mit Extravasation weißer Blutzellen und an Stellen, wo sich die Verlangsamung zum Stillstand, zur Stase, steigert, mit Extravasation roter Blutkörperchen verbunden ist. Schon sehr früh stellt sich im infizierten Gebiet Capillarneubildung ein, bald darauf Vermehrung der fixen Zellen. Die jeweils vorhandenen Zellen setzen Knötchen zusammen, deren es bacillenhaltige und bacillenfreie gibt, sowie capillarhaltige und capillarfreie. In dem infizierten Gebiet verhalten sich die Gefäße und Capillaren anders wie in einer normalen Gegend, insofern als sie durch physikalische und chemische Reize nicht mehr zur Kontraktion, sondern zur Erweiterung gebracht werden, während sich der Blutstrom verlangsamt und in Stase übergeht. Mit dem Fortschritt der Zeit hört die Verlangsamung des Blutes, die Erweiterung der Strombahn, die Extravasation und Bindegewebsvermehrung auf, aber die Reaktion der Gefäße und der an Zahl abnehmenden Capillaren behält in dem von uns berücksichtigten Zeitraum einen abnormen Charakter.

Wir haben nun die Aufgabe, den teils am lebenden Tier, teils an 
fixierten und gefärbten Präparaten studierten Prozeß, wie er oben ausführlich geschildert und zuletzt in kurzen Worten zusammengefaßt ist, zu erläutern, d. h. ihn an bekannte Tatsachen der Physiologie und Pathologie anzugliedern und dadurch soweit wie möglich verständlich zu machen ${ }^{1}$ ).

Die Experimente haben damit begonnen, daß pathologische Reize gesetzt worden sind, die Tuberkelbacillen, deren Reizwirkung man mit Recht als vorwiegend chemische ansieht, und, in einem Teil der Versuche, die akzessorischen (physikalischen) Reize, wie sie die Benetzung und Bepinselung mit sich gebracht haben. Die Reize haben, wie sich aus den Protokollen ergibt, zuerst Veränderungen an der Blutstrombahn, an ihrer Weite und der Geschwindigkeit ihres Inhaltes, hervorgebracht.

Es sind ausschließlich Mesenterialgefäße gewesen, die wir beobachtet haben, denn auch die Gefäße des völlig zwischen den Blättern des Mesenteriums gelegenen Kaninchenpankreas sind Äste der Mesenterialarterien und -venen. Die Physiologie lehrt, daß die Gefäße im Pankreas vom Nervus splanchnicus und vom Nervus vagus innerviert werden, und da $B$ in beiden Nerven sowohl Constrictoren als Dilatatoren enthalten sind. Ebenso wie von dem am meisten von uns benutzten Mesenterium der Pankreasgegend und den zwischen seinen Blättern außer der Speicheldrüse gelegenen Gebilden, wie Fettgewebe und Nerven, ist es von den anderen Stellen des Bauchfelles, die wir untersucht haben, nicht zweifelhaft, daß die Gefäße mit verengenden und erweiternden Nerven versehen sind.

Die oben erwähnten Reize sind nach der Lehre der allgemeinen Nervenphysiologie geeignet, auf das Nervensystem, auch der Blutstrombahn, zu wirken. Wie erklären sich nun auf der uns somit von der Physiologie angewiesenen Basis, der Wirkung von Reizen auf das Gefäßnervensystem, die von uns beobachteten Vorgänge an der Blutstrombahn?

Wir sehen in den Protokollen als die erste beobachtete Wirkung angegeben, daß sich die Strombahn erweitert und die Strömung verlangsamt. Die Erweiterung haben wir nach dem Gesagten auf einen Reizungszustand der Dilatatoren zurückzuführen, ihr Grad ist zunächst nicht stärker als derjenige, der durch eine Dilatatorenreizung im physiologischen Leben, wie er z. B. bei starker Funktion einer Drüse durch mikroskopische Messung der Weite oder im funktionierenden Muskel durch Messung der Blutmenge nachgewiesen werden kann, zustande kommt. Was aber diese Form der Erweiterung von der uns hier beschäftigenden unterscheidet, ist die gleichzeitige Verlangsamung und der Verlust der Erregbarkeit der Constrictoren, den wir in unseren Reaktionsversuchen festgestellt haben. Da es, wie eben hervorgehoben, nicht

1) Vergleiche die Figuren 1-4. 
der Grad der Weite ist, aus dem die Verlangsamung verständlich würdë; da ferner weder am Blute, noch am Gewebe etwas aufällt, was den Eintritt der Erweiterung erklären könnte, so bleibt nur die Vorstellung übrig; daß die Verlangsamung in ursächlichem Zusammenhange mit dem Verlust der Erregbarkeit der Constrictoren steht. Dieser Zusammenhang kann nur so aufgefaßt werden, daß die Gefäßnerven nicht nur die Weite eines Stromgebietes bestimmen, sondern auch die Arbeitsleistung seiner Wand beeinflussen. Eine solche Arbeitsleistung ist von den mit glatter Muskulatur versehenen Arterien und Venen nach Analogie der anderen muskulären Organe des Körpers anzunehmen, ist durch Versuche wahrscheinlich gemacht und dürfte auch der Capillarwand zuzusprechen sein ${ }^{1}$ ), da die Strömungsgeschwindigkeit in den Capillaren in hohem Maße von der in den Arterien herrschenden unabhängig ist und ebensowenig wie die Geschwindigkeit in den Gefäßen von dem Grade der Erweiterung bestimmt wird.

Mit der so verständlich gemachten und auf andere Weise nicht erklärbaren Stromverlangsamung ist die Extravasation von weißen Blutkörperchen ursächlich verbunden, da ausschließlich bei Verlangsamung der Blutströmung, wie die hier allein maßgebenden Versuche am lebenden Tier ergeben, ihr Haften an der Wand kleiner erweiterter Venen und erweiterter Capillaren, die notwendige Vorbedingung der Extravasation, zustande kommt. Wie sich diese Extravasation im einzelnen vollzieht, dürfen wir hier als nicht unmittelbar zur Sache gehörig zu erörtern unterlassen.

Unsere Protokolle lehren, daß die verlangsamte Strömung des Blutes hier und da zum Stillstand kommt und daß diese Steigerung der Verlangsamung rund der Stillstand selbst mit Extravasation roter Blutkörperchen einhergeht. In denjenigen Versuchen, in denen lediglich die

1) In bezug auf die Arbeitsleistung der Gefäß- und Capillarwand vgl. Grützner, Betrachtungen über die Bedeutung der Gefäßmuskeln und ihrer Nerven (Deutsches Archiv f. klin. Med. 89. 1907) und die beiden oben angeführten Abhandlungen von M. Natus. - Neuerdings hat Hasebroek eine Monographie „,Uber den extrakardialen Kreislauf des Blutes vom Standpunkte der Physiologie, "Pathologie und Therapie“ (Jena 1914) veröffentlicht, in der er „,ein Gesamtbild des Kreislaufes" unter dem Gesichtspunkte der Arbeitsleistang auch der Gefäße entwirft, freilich nicht mit rein physiologisch-naturwissenschaftlichen, sondern vorwiegend mit biologisch-naturphilosophischen (teleologischen) Mitteln. Dieser Darstellung dienen, außer Hürthles Untersuchungsergebnissen aus der jüngsten Zeit (1913), die der Autor aber selbst' nicht als eindeutig hinstellt, besonders die von mir mit Natus (1910) gemachten Beobachtungen (Natus, l. c.) als experimentelle Grundlagen; dagegen ist das reichhaltige Material, das meine übrigen Mitarbeiter vorher und nachher zur Stütze der Hypothese herbeigebracht haben, von Hasebroek unerwähnt geblieben. Aus demselben geht hervor, daß lokale Kreislaufstörungen (und das sind im strengen Sinne alle Kreislaufstörungen) nur mittels der Anerkennung einer Beeinflussung der lokalen Triebkräfte von seiten des Gefäßnervensystems begriffen werden können. 
Tuberkelbacillen und die mit den Infizierverfahren verbundenen akzessorischen Reize angewandt worden sind, nur zuweilen und in sehr geringer Ausdehnung beobachtet, ist der Vorgang der Stase und Diapedesisblutung der die ganze Strombahn betreffende Abschluß unserer Reaktionsversuche gewesen, also der Versuche, in denen ein weiterer chemischer Reiz (namentlich Suprarenin) hinzugetreten ist, der seinerseits an den Gefäßnerven angegriffen hat. Da Stillstand lediglich eine quantitative Steigerung von Verlangsamung darstellt, ist es geboten, die oben abgegebene hypothetische Erklärung auch hier anzuwenden und die Ursache der Stase in dem bei unveränderter Reizung nur hier und da auftretenden, bei gesteigerter Reizung allgemein werdenden Verlust der Erregbarkeit auch der Dilatatoren, also des gesamten Gefäß- und Capillarnervensystems, zu sehen, gemäß der von Ricker und Natus aufgestellten Theorie der Stase und der mit ihr eng verbundenen Diapedesisblutung, auf deren ausführliche Begründung wir verweisen.

Außer den soeben besprochenen, wie wir gesehen haben, funktionellen Alterationen am Gefäß- und Capillarsystem und ihren Folgezuständen haben wir Vermehrungsvorgänge am Gewebe festgestellt, von denen uns zuerst die so überraschend früh auftretende und so beträchtliche Neubildung von Capillaren zu beschäftigen hat. Es entstehen die Capillaren aus Sprossen vorgebildeter Capillaren, kleiner Arterien und Venen; die anfangs soliden, dann mit zunächst engem, darauf sich erweiterndem Lumen versehenen Sprossen verbinden sich zu Schlingen, worauf sich der Vorgang von diesen aus wiederholt ${ }^{1}$ ). Läßt sich nun an der Hand der Beobachtungen ein Verständnis für diesen Vorgang gewinnen?

Capillarneubildung erfolgt nur bei bestehender Hyperämie von einer genügenden Stärke und Dauer. Ist es diejenige Erweiterung der Strombahn, bei der diese beschleunigt durchlaufen wird, liegt also eine Dilatatorenreizung ohne Aufhebung der Erregbarkeit der Constrictoren vor, so bleibt die Capillarneubildung, z. B. in einer wachsenden Niere nach Exstirpation des Schwesterorgans, gering. Die Mächtigkeit der Capillarneubildung, wie wir sie beschrieben haben und wie sie z. B. auch dem Granulationsgewebe eigentümlich ist, ist mit einer Hyperämie anderer Art verbunden, die wir oben in ihrer Abhängigkeit von einer Dilatatorenreizung bei gleichzeitiger Aufhebung der Erregbarkeit der Constrictoren kennen gelernt haben. Es liegt nahe, in der Hyperämie, die eine verstärkte Beziehung zwischen Blut und Endothel bedeutet, die Ursache, in den Unterschieden zwischen den beiden Typen der Hyperämie die Erklärung der graduellen Verschiedenheit der beiden Formen der Capillarneu-

1) Die hauptsächlichen: Formen des Zusammenhanges der neugebildeten Capillaren mit Arterien und Venen, auch neugebildeten, haben wir durch dị beigegebenen 5 schematischen Figuren veranschaulicht, die nach bei Beobachtung des Mesenteriums des lebenden Tieres entworfenen Skizzen angefertigt sind. 


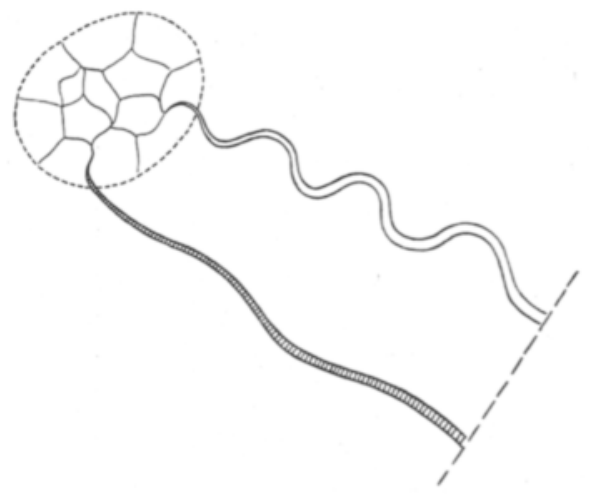

Fig. 1.

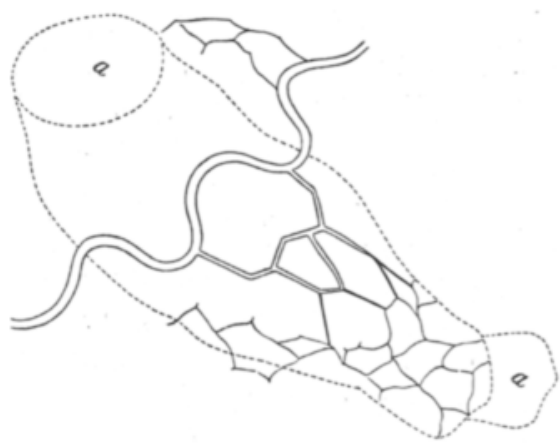

Fig. 3.

Erläuterung:

Umriß der in ganz oder nahezu capillarfretem Mesenterium gelegenen Tuberkel mit einer gestrichelten Linie angegeben. Arterie quer, Vene nicht gestrichelt.

Fig. 1: Fine Arterie und eine Vene treten (aus dem Fettgewebe) in das Capillarnetz des Tuberkels ein (4 Tage nach der Infektion durch Bepinselung).

Fig. 2: Die Capillaren des Tuberkels gehen ausschlieblich von der Arterie aus und umspinnen die stark geschlangerte Vene (13 Tage nach der Infektion durch Injektion).

Fig. 3: Die Capillaren des - langlichen Tuberkels gehen ausschlieblich von einer stark geschlängelten Vene aus. $a, a$ : zwei besonders dichte Bezirke des Tuberkels (5 Tage nach der Infektion durch Bepinselung).

Fig. 4: Ein Arterien-, zwei Venenästchen lösen sich in das Capillarnetz des Tuberkels auf (6 Tage nach der Infektion durch Bepinselung).

Fig. 5: Eine Arterie und eine Vene sind durch ein Capillarnetz verbunden, das sich in einen Teil der peripherischen Zone eines Tuberkels hineinerstreckt. In der Nahe Netz neugebildeter Capillaren, von einem Segment der stark geschlingelten Vene ausgehend, ohne daß ein Tuberkel vorhanden wăre (3 Tage nach der Infektion durch Benetzung). 
bildung zu sehen. Da nämlich beim 2. Typus der Grad der Erweiterung der Blutstrombahn meist beträchtlich stärker und die Erweiterung stets ganz oder nahezu dauerhaft ist, während beim 1. Typus, wie er beim physiologischen Wachstum herrseht, infolge des Erhaltenseins der Erregbarkeit der Constrictoren Perioden der Enge der Strombahn eingeschaltet sind und die Erweiterung im allgemeinen geringer bleibt, so ist im ersten Falle die Berührung der Capillar- und Gefäßwand mit dem Blute oder vielmehr der die Bildungsstoffe enthaltenden Blutflüssigkeit intensiver, als im zweiten; es kommt hinzu, daß im zweiten Falle, bei dem pathologischen Typus der Hyperämie, umgekehrt wie es von der physiologischen Hyperämie anzunehmen, der Seitendruck erhöht ist, wie La pinsky $\mathrm{y}^{\mathbf{1}}$ ) an der nach Ausschaltung der Constrictoren und Reizung der Dilatatoren erweiterten, verlangsamt durchströmten Strombahn der Schwimmhaut des Frosches durch Messung nachgewiesen hat. Man darf sich vorstellen, daß mit der stärkeren und dauerhafteren Beziehung der Mutterzellen zu der das Material zum Wachstum enthaltenden und in die Zellen befördernden Blutflüssigkeit das so starke Wachstum der Endothelzellen der Gefäße und Capillaren, das wir beobachtet haben, in ursächlichen Zusammenhang steht.

Haben wir für die Neubildung der Capillaren die Hyperämie als Ursache herangezogen, so dient sie uns auch dazu, ein erstes Verständnis für die Vermehrung der Bindegewebszellen und -fasern zu gewinnen. Da Zell- und Faservermehrung nichts anderes darstellt als eine in bestimmten Strukturformen erfolgende Anlagerung von Substanzen, die aus einem strukturlosen flüssigen Medium, einem Transsudat, hervorgehen, so ist die Hyperämie mit ihrer verstärkten Bildung von Transsudat als Grundlage des im einzelnen unbekannten Vorganges eine nicht nur berechtigte, sondern gebotene Vorstellung, die von vielen Erfahrungstatsachen der Pathologie über die Bindegewebsvermehrung bei chronischer Hyperämie gestützt wird.

Mit dem Vorschreiten der Zeit nähert sich die Strombahnweite und Strömungsgeschwindigkeit wieder der Norm an. Die Ursache davon kann nur in einer Abschwächung des Reizungszustandes der Gefäßnerven liegen, die daraus verständlich wird, daß Bacillen außerhalb von Knötchen nicht mehr nachweisbar sind, während man von den in die dichten Knötchen eingeschlossenen Bacillen, zumal den im zerfallenen, d. h. außer Strömung gesetzten Zentrum gelegenen, annehmen darf, daß sie weniger chemische Reizmittel nach außen abgeben; auch mag eine sogenannte Gewöhnung des Nervensystems eintreten, die die fremdartigen Reize immer schwächer und die physiologischen Reize wieder stärker wirksam werden läßt. Da wir die Extravasation weißer

$\left.{ }^{1}\right)$ M. Lapinsky, Studien über die lokale Blutzirkulation im. Bereiche gelähmter Nerven, Archiv f. Anat. u. Physiol., physiol. Abtlg., Suppl. 1899. 
und roter Blutkörperchen, die Capillar- und Bindegewebsvermehrung von dem des näheren besprochenen Typus der Hyperämie abhängig gemacht haben, so verstehen wir, daß mit ihrem Verschwinden die Extravasation aufhört, die Capillaren und fixen Zellen sich nicht weiter vermehren, sondern z. T. zurückbilden. Was, gemessen an dem $\mathrm{Zu}$ stande vor der Infektion, als vermehrtes Gewebe zur Zeit des Abschlusses unserer Versuche vorhanden war, wird in seiner Existenz unterhalten von dem noch übrigen, gegen die Norm vermehrten Teil der Capillaren und den Gefäßen, die noch immer leicht vermehrt durchströmt sind und ein vergrößertes Capillarnetz speisen.

Es bleiben nun noch die Knötchen, Tuberkel, zu besprechen übrig. Nachdem wir ihrer bereits in den bisherigen allgemeinen Zusammenfassungen gedacht haben, möchten wir hier im Zusammenhange ihre wichtigsten speziellen Eigentümlichkeiten teils wiederholen, teils ergänzend hinzufügen. Es ist bereits erwähnt worden, daß die Tuberkel aus den jeweils vermehrt im Mesenterium anwesenden Zellen zusammengesetzt sind, demgemäß also zuerst aus extravasierten Zellen, nach dem Eintritt der Bindegewebsvermehrung aus neugebildeten fixen und extravasierten Zellen; später sind es vorwiegend vermehrte Bindegewebszellen, denen Lymphocyten beigemischt sind, die die Tuberkel aufbauen. Es sind namentlich in den beiden ersten Versuchsreihen schon in den ersten Tagen neugebildete Capillaren, sei es nur in der peripherischen Zone der Tuberkel, sei es diese ganz in Maschenform durchziehend, nachgewiesen worden; besonders hervorzuheben sind die in capillarfreiem Gewebe gelegenen Tuberkel mit ihrem Capillarnetz, das eigene Zu- und Abflußwege in Gestalt weiterer Capillaren oder Gefäßchen besaß. Mit dem Fortschritt der Zeit verschwanden die Capillaren, nachdem Stase in ihnen eingetreten, aus dem zentralen Teil der Tuberkel und fanden sich beim Abschluß der Versuche nur in der peripherischen, vorwiegend aus Spindelzellen bestehenden Zone derselben, und zwar großer oder kleiner Tuberkel.

Außer den capillarhaltigen sind stets capillarfreie Knötchen vorhanden gewesen.

Wenn wir diese Eigentümlichkeiten der Tuberkel überblicken, so erkennen wir, daß sie sich im wesentlichen nur durch ihre Form von der Umgebung unterscheiden. Wir wollen daher mit der Form beginnen und versuchen, ein Verständnis derselben zu gewinnen.

Es könnte zunächst daran gedacht werden, daß es einzig und allein die Bacillen sind, die irgendwie die Gruppierung der Zellen veranlassen. Diese Vorstellung scheitert daran, daß wir sehr oft vollkommen durchsichtige Tuberkel, in denen anwesende Bacillen der Beobachtung nicht entgangen wären, und zwar kleinste und etwas größere, getroffen haben, in denen Bacillen völlig gefehlt haben. Auf der anderen Seite sind 
Bacillen im Zentrum der Tuberkel ein so häufiger Befund, daß es nicht angeht, eine Bedeutung jener für die Formierung von Knötchen ganz in Abrede zu stellen. Wie sind nun die Befunde miteinander zu vereinbaren?

Um diese Frage zu beantworten, müssen wir uns daran erinnern, daß wir in den zuerst auftretenden Leukocyten in Bewegung befindliche Zellen vor uns haben; als die bewegende Kraft sehen wir die Strömung in der vermehrten Gewebsflüssigkeit an, die sich aus den Capillaren ergießt und von den Lymphgefäßen aufgenommen wird; diese Flüssigkeit befördert, wie aus unseren Präparaten hervorgeht, die extravasierten Zellen durch das ganze Mesenterialgebiet hindurch. Es ist nun bei der großen, aber nicht übergroßen und dadurch Abstände ausschließenden Zahl der Leukocyten fast selbstverständlich, daß dieselben auf ihrem Wege von der Stelle der Extravasation zu den spärlichen Lymphgefäßen da und dort zusammentreffen und vermöge ihrer Klebrigkeit aneinander haften, sowie die Haftfläche für später heranbeförderte abgeben; auf diese Weise gelingt ein Verständnis für die frühesten aus extravasierten Zellen bestehenden Tuberkel. Diese Betrachtungsweise auch auf die fixen Zellen bis zu einem gewissen Grade anzuwenden, scheint uns trotz ihrer im Vergleich zu den Leukocyten zweifellos geringeren Verschiebbarkeit berechtigt; so dürfte auch in bezug auf diese mit dem Aneinanderhaften sich treffender Zellen die Grundlage für die Entstehung von Knötchen gegeben sein, die sich dann im wesentlichen durch Vermehrung vergrößern, wobei weiße Blutzellen an der Peripherie festgehalten und später eingeschlossen werden können.

Wenn es auf diese Weise gelingt, die Entstehung der bacillenfreien Knötchen verständlich zu machen, so bedarf es, um auch die häufige zentrale Lage von Bacillen bereits in kleinsten Knötchen aufzuklären, nur der weiteren Annahme, daß auch Bacillen und namentlich Häufchen von solchen in Bewegung befindliche Zellen aufzuhalten vermögen, sei es als mechanisches Hindernis, wie dies von den Tuscheteilchen anzunehmen ist, um die sich in unseren Kontrollversuchen Knötchen gebildet haben, sei es vermöge einer gewissen Klebrigkeit ihrer Substanz oder in die nächste Nähe ausges̀chiedener Stoffe, - die dann die Bacillen von den Tuschepartikelchen unterscheiden und der ungleich größeren Häufigkeit der Knötchen in einem mit Tuberkelbacillen infizierten mesenterialen Bindegewebe zugrunde liegen würden.

Wir geben sehr gerne zu, daß diese Darstellung zu einem großen Teil hypothetisch und Einwänden ausgesetzt ist, möchten aber auch darauf hinweisen, daß bessere Erklärungen in der Literatur nicht vorliegen. Ist doch eine chemotaktische Wirkung der Tuberkelbacillen im Tierkörper nicht nachgewiesen, ganz abgesehen von den sie uns unannehmbar machenden Einwänden, denen die Lehre von der Chemotaxis im 
tierischen Körper überhaupt ausgesetzt ist; auch würde diese Hypothese den bacillenfreien Knötchen und den, wie unsere Kontrollversuche ergeben haben, ohne bacilläre Infektion auftretenden Knötchen nicht gerecht werden. Ebensowenig kann der ,Gewebsdruck“" die Entstehung der Knötchenform verständlich machen, er kann höchstens auf schon angelegte oder ausgebildete Knötchen wirken.

Von den sonstigen Eigenschaften der Tuberkel bedarf einer Besprechung nur noch das häufige Vorkommen von Capillaren in ihnen, das mit der weit verbreiteten Vorstellung von der ,Gefäßlosigkeit“" der Tuberkel in Widerspruch steht. Unsere Untersuchungen am lebenden Tier sind es gewesen, denen wir diesen Nachweis zu verdanken gehabt haben, während schon im Flächenpräparat der Capillargehalt von Tuberkeln schwerer und in Schnittpräparaten, wie wir uns überzeugt haben, überhaupt nicht mit genügender Sicherheit zu erkennen war.

Die wichtigste hierher, gehörige Tatsache ist, daß der Capillargehalt keine notwendige Eigentümlichkeit des Tuberkels ist, sondern nur eine häufige; entsteht ein Tuberkel in capillarfreien Teilen des Mesenteriums, wie sie stets vorhanden sind, sogar noch auf der Höhe der Capillarneubildung, so ist und bleibt er capillarfrei, entsteht er im Gebiet der neugebildeten Capillaren, z. B. in dem Capillarmantel, wie er oft ein Gefäßpaar umhüllt, so ist er häufig von solchen durchzogen. Einer besonderen Erläuterung bedürfen aber diejenigen Tuberkel, die ein in sich geschlossenes Capillarsystem (vgl. die Schemata) besitzen; hier kann der Gedanke wachwerden, daß etwa die Bacillen die Neubildung der Capillaren aus einer umschriebenen Strecke einer Arterie oder Vene verursacht und ihre Wachstumsrichtung bestimmt hätten. Indessen diese Auffassung wird dadurch unhaltbar, daß man nicht selten eine ebensolche umschriebene Capillarneubildung feststellt, ohne daß Bacillen anwesend sind und ohne daß sich daselbst ein Tuberkel ausgebildet hat. Die umschriebene Capillarneubildung ist somit in Eigentümlichkeiten der Gefäße bedingt, sie ist lediglich ein Ausdruck ihrer uns in den Reaktionsversuchen und sonst deutlich vor Augen getretenen segmentären Differenziierung, die eine physiologische Grundlage haben dürfte, welche nur im Nervensystem der Gefäße gesucht werden kann.

Es bleibt nun noch übrig, der beobachteten Zerfallsveränderungen zu gedenken.

Ihren größten Umfang erreichen dieselben an den extravasierten Zellen, weißen und roten. Mögen sie auch z. T. in Lymphgefäße gelangen und weggeführt werden, wir haben schon sehr früh so zahlreiche Leukocyten mit Kernen, die in Chromatinkörnchen verwandelt waren, angetroffen, daß ihr späteres Fehlen zu der Zeit, wo keine Extravasation mehr stattfindet, jedenfalls zum Teil auf Zerfall im Gewebe zurückzuführen ist. Die Ursache dieses Zerfalls ist wohl vorwiegend in dem 
besonderen Charakter dieser Zellart begründet, die im Blute schon im physiologischen Leben in großer Zahl zugrunde geht, um so mehr wohl in dem veränderten Medium nach der Extravasation. - Der rasche Zerfall der extravasierten roten Blutkörperchen dürfte ähnlich aufzufassen sein.

An zweiter Stelle ist des Verschwindens von Capillaren zu gedenken, das, wie oben hervorgehoben, in sehr großem Umfange eintritt und dazu führt, das Capillarnetz weitmaschig zu machen. Dieser Capillarschwund erfolgt nach vorausgegangener Stase, indem, wie wir uns überzeugt haben, mit der Auflösung des Staseblutes auch die Capillarwand immer undeutlicher wird; offenbar gehört also die Berührung mit fließendem Blut dazu, daß die Capillarwand erhalten bleibt, so daß die oben erörterte Ursache der Stáse auch die Ursache des Capillarschwundes ist. Zweifellos wirkt ferner die beträchtlich abnehmende Erweiterung der Gefäße in der späteren Zeit so, daß ein Teil des Capillarnetzes nicht mehr durchströmt wird und darum schwindet; dies geht besonders deutlich aus unseren Beobachtungen an der Grenze der Mäntel neugebildeter Capillaren, wie sie Gefäße umgeben und an capillarfreies Mesenterium anstoßen, hervor.

Den größten Umfang erreicht der Zerfall im zentralen Teil der Tuberkel. Wenn wir von den allerersten, aus polymorphkernigen Zellen zusammengesetzten Tuberkeln absehen, deren früher Zerfall in den obigen Bemerkungen über die Hinfälligkeit dieser Zellart besonders nach ihrer Extravasation seine Aufklärung findet, so zerfallen die mit einem Capillarnetz durchzogenen Tuberkel offenbar deswegen, weil die vorwiegend in ihrem Innern nachweislich auftretende Stase daselbst die Beziehung der neugebildeten Zellen zum Blute und der austretenden Blutflüssigkeit aufhebt. Die gleiche Wirkung muß die Verminderung der aus den Capillaren austretenden und das mesenteriale Bindegewebe durchströmenden Flüssigkeit auf die capillarfreien Tuberkel ausüben, sofern sich ein Mißverhältnis zwischen der Menge der Flüssigkeit und der von ihr in ihrer Existenz zu erhaltenden Zellen herausstellt; ein solches Mißverhältnis wird aber, wie mehrfach betont, mit dem Fortschritt der Zeit herbeigeführt und wird sich namentlich im zentralen Teil des Tuberkels, der der dichteste und somit am schwersten der Flüssigkeit zugängliche ist, bemerkbar machen.

Auch die vermehrten fixen Zellen außerhalb der Tuberkel nehmen, wie der Vergleich der Präparate ergibt, mit dem Fortschritt der Zeit an Zahl ab; in je einem Versuche aus der 2. und 3. Reihe haben wir sogar den direkten Hinweis auf einen Schwund jener Zellen in starker Deformierung der Kerne und Kernzerfall in Chromatinkörnchen gefunden. Dieselben Ursachen, die wir soeben für die Rückbildungsvorgänge in Tuberkeln angeführt haben, sind geeignet, auch den letzterwähnten Vorgang zu erklären. 
Als wir die Entstehung der Knötchenform erörterten, haben wir bereits des Vorkommens bacillenfreier Tuberkel gedacht; sie sind ein keineswegs seltener Befund in allen unseren Präparaten gewesen, auch in jüngsten Tuberkeln, so daß es nicht angeht, einen nachträglichen Untergang von Bacillen anzunehmen. Man wird vielmehr durch diese Erfahrung zu der Auffassung gedrängt, daß wie die Agglutination der Zellen, deren wir bereits in diesem Sinne gedacht, so auch die weitere Entwicklung der Tuberkel ohne die Anwesenheit der Bacillen in ihnen vor sich gehen kann, eine Auffassung, die für uns, die wir die Hyperämie als Ursache der Zellvermehrung ansehen, nichts befremdendes hat.

Dagegen bleibt es sehr auffällig und unerklärlich, daß wir mehrere Male überhaupt keine Bacillen in ganzen großen Flächenpräparaten haben finden können.

\section{Teil.}

Zu dem zweiten Teil unserer Untersuchungen haben uns, außer den besprochenen Erfahrungen über die abnorme Reaktion der Strombahn im tuberkulösen Gebiet, einige Beobachtungen angeregt, die wir in der ersten Versuchsreihe gemacht und oben mitgeteilt, bisher aber unerörtert gelassen haben; sie sollen hier noch einmal Platz finden.

Im 4. Versuch, 6 Tage nach der Bepinselung, und im 6. Versuch, 13 Tage nach derselben, haben wir eine vom Infektionsort weit entfernt gelegene Dünndarmschlinge herausgeholt und das Mesenterium, an dessen Aussehen, Strombahn und Strömungsgeschwindigkeit nicht das geringste Abnorme auffiel, mit Suprareninlösung im 1. Falle, mit Sublimatlösung im 2. Falle berieselt: es hat sich eine Abschwächung der Reaktion, und zwar eine Verzögerung der Verengerung ergeben, die Erregbarkeit der Constrictoren war also herabgesetzt. Als Ursache konnte nur eine Beeinflussung des Gefäßnervensystems von dem infizierten Duodenalmesenterium her in Betracht kommen, die ihrerseits durch gelöste, in das Blut aufgenommene Produkte der Tuberkelbacillen, sei es ihres Stoffwechsels, sei es ihres Zerfalles, hervorgerufen sein konnte.

Die hierdurch angeregten Versuche sind mit (dem glycerinfreien) Tuberkulol B (Merck ${ }^{1}$ ) und mit Alttuberkulin (Merck ${ }^{2}$ ) angestellt

1) Tuberkulol B (Präparat von Landmann) stellt die wässerigen Extrakte dar, ,welche durch fraktionierte Extraktion der Bakterienleiber bei schrittweise steigender Temperatur gewonnen werden und welche also die bei niederer Temperatur gewinnbaren Extraktein völlig unveränderter Form enthalten, daneben aber auch die nur bei höherer Temperatur darstellbaren Endotoxine."

2) Die im Vergleich zur Verwendung des Tuberkulins beim Menschen hohen Dosen sind nach der allgemeinen Erfahrung dem Kaninchenkörper, der z. B. $5 \mathrm{ccm}$ Alttuberkulin ohne schwerere Schädigung erträgt, angemessẹn und auch in den Versuchen anderer Autoren angewandt worden. 
worden, und zwar teils mit Berieselung des Mesenteriums, teils mit subcutaner Injektion, sowohl bei gesunden als bei mit Tuberkelbacillen, und zwar bovinen, infizierten Tieren. Nach der Tötung der im gesunden Zustande zum Versuche verwandten Kaninchen hat die sorgfältig vorgenommene Sektion niemals etwas Tuberkulöses nachgewiesen.

Wir beginnen mit einer Ubersicht über die Beobachtungen bei den Tuberkulolversuchen.

A. Versuche an gesunden Tieren.

I. Berieselung des Duodenalmesenteriums mit Tuberkulollösungen und mikroskopische Besichtigung desselben.

1. Tuberkulollösungen von verschiedener Konzentration zwischen 1 : 5000 und $1: 50 \mathrm{ccm}$ Kochsalzlösung, Berieselung auf je 6 Minuten: Kein Einfluß auf Weite und Geschwindigkeit.

2. Berieselung mit Tuberkulol 1 : 25: Nach 1 Minute leichte Verengerung der Arterie und Capillaren, leichte Verlangsamung des Venenstromes. In den folgenden 5 Minuten Zunahme der Verengerung; die Weite der Arterie, die vor der Berieselung mit Tuberkolul 2 gemessen hatte, schwankt zwischen 1 und $1 \frac{1}{2}$. Beim U̇bergang zur Berieselung mit Kochsalzlösung stellt sich schnell der (normale) Ausgangszustand wieder her.

Berieselung derselben Stelle mit Tuberkulol 1 : 10: Nach 1/2 Minute verengt sich die Arterie auf 1 und behält dieses Maß während der 4 Minuten langen Berieselung. Nach Utbergang zur Kochsalzlösung Wiederherstellung des (normalen) Ausgangszustandes.

3. Berieselung mit Tuberkulol 1:25: Vor der Berieselung langsamer Strom. Nach 5 Minuten langer Berieselung nimmt die Verlangsamung zu und ist nach 6 und 8 Minuten sehr beträchtlich. - Unter Berieselung mit Kochsalzlösung wird die Strömung wieder etwas schneller.

II. Subcutane Injektion von Tuberkulol und mikroskopische Besichtigung des Duodenalmesenteriums.

1. 4 Stunden nach Injektion von $0,1 \mathrm{ccm}$ Tuberukulol: Nichts auffälliges an Strombahnweite und Strömungsgeschwindigkeit.

Berieselung mit Suprareninlösung: Sofortiger Verschluß der Arterie und Capillaren (wie beim normalen Tier).

2. 24 Stunden nach Injektion von $0,1 \mathrm{ccm}$ Tuberkulol: Nichts auffälliges an Strombahn und Strömungsgeschwindigkeit.

Berieselung mit Suprareninlösung: Starke Verengerung der (sehr kleinen) Arterie, $1 / 2$ Minute später ist das Ausgangsma $ß$ wiederhergestellt, der Venenstrom aber verlangsamt. Nach 2 Minuten ist die Arterie etwas weiter als vor der Reaktion, der Venenstrom verlangsamt.

Nach Übergang zur Berieselung mit Kochsalzlösung tritt Verschluß der Arterie und Capillaren ein und hält an.

3. 24 Stunden nach Injektion von $0,1 \mathrm{ccm}$ Tuberkulol: Nichts auffälliges.

Berieselung mit Suprareninlösung: Nach 1/2 Minute kurzer Verschluß der Arterie und Capillaren, dann erweitern sich Arterie und Capillaren wieder, ohne die Ausgangsweite zu erreichen. Strömung leicht verlangsamt.

4. 24 Stunden nach Injektion von $2,5 \mathrm{ccm}$ Tuberkulol: Nichts auffälliges an Strombahnweite und Strömungsgeschwindigkeit.

Berieselung mit Suprareninlösung: Nach $3 / 4$ Minute Arterie leicht verengt, Venenstrom leicht verlangsamt. Nach $4 \frac{1}{2}$ Minuten Arterie wieder von 
der gleichen Weite wie vor der Suprarenineinwirkung, Venenstrom leicht verlangsamt.

Kochsalzlösung: Nach 21/2 Minuten Arterie so stark verengt, daß die Strömung fast aufhört. Im Verlauf der folgenden Minuten ist die Arterie zeitweilig verschlossen, unter Aufhebung des Venenblutstromes, zeitweilig sehr stark verengt bei stark verlangsamter Strömung.

B. Versuche an tuberkulösen Tieren (Infektion des Duodenalmesenteriums durch Benetzung mit Bacillenaufschwemmung).

I. Berieselung mit Tuberkulol.

1. 8 Tage nach der Infektion, Tuberkulol $1: 50$. Duodenalmesenterium makroskopisch leicht getrübt, wie sich mikroskopisch ergibt, durch die Anwesenheit von Tuberkeln. Beobachtet wird ein Tuberkel mit Capillaren nahe einer kleinen Arterie und Vene.

Berieselung mit Tuberkulol 1 : 50: Nach 3/4 Minuten Verengerung der Arterie, nach 1 Minute Verlangsamung des Arterien-, Capillar- und Venenstromes, nach $1 \frac{1}{2}$ Minuten treten einzelne Stasecapillaren und eine Ekchymose auf. In den folgenden zwei Minuten wird die Arterie wieder weiter, die Strömung wieder etwas schneller, in den meisten Stasecapillaren kommt die Strömung wieder in Gang.

Berieselung mit Kochsalzlösెung: Es stellt sich der Zustand wie vor der Tuberkulol-Berieselung wieder her.

Bei einer zweiten Berieselung der nämlichen Stelle auf 4 Minuten: Dieselbe Wirkung wie oben beschrieben; sie verschwindet auf Berieselung mit Kochsalzlösung.

2. 9 Tage nach der Infektion, Tuberkulol $1: 25$.

Beobachtet wird ein großer zentral trüber Tuberkel mit vielen (neugebildeten) Capillaren an der Peripherie und kleiner Arterie und Vene in seiner Nähe.

Berieselung mit Tuberkulol: 1:25. Bei 8 Minuten langer Einwirkung und während der nachfolgenden Kochsalzberieselung keine Änderung der Weite und Geschwindigkeit.

II. Subcutane Injektion von Tuberkulol.

1. Infektion vor $38 \mathrm{Stunden.} \mathrm{Beobachtung} 5 \mathrm{Stu}$ den nach der subcutanen Injektion von 0,1 Tuberkulol. Spärliche Tuberkel meist mit Capillaren. Keine Verlangsamung des Blutstromes, keine Stasecapillaren oder Ekchymosen.

Berieselung mit Suprareninlösung: Nach 1/4 Minute fast vollständiger Verschluß der Arterie.

2. Infektion vor 14 Tagen. Beobachtung 1 Tag nach der subcutanen Injektion von $0,1 \mathrm{com}$ Tuberkulol.

Nichts auffälliges an der Strömung und Weite.

3. Infektion vor 21 Tagen. Beobachtung 2 Tage nach der subcutanen Injektion von $0,4 \mathrm{ccm}$ Tuberkulol.

4. Infektion vor 12 Tagen. Beobachtung 1 Tag nach der subcutanen Injektion von $1 \mathrm{ccm}$ Tuberkulol. Weite.

Auch in diesen beiden Versuchen nichts auffälliges an der Strömung und

5. Infektion vor 12 Tagen. Beobachtung 2 Tage nach der subcutanen Injektion von 1,5 com Tuberkulol.

Sehr starke allgemeine Capillarneubildung, ziemlich zahlreiche distinkte und verwaschen begrenzte Tuberkel mit Capillaren in der peripherischen Zone.

Die ganze Strombahn auffällig erweitert und stark verlangsamt durchströmt. Hier und da Stasecapillaren und kleine Ekchymosen, die sich während des Versuches nicht vermehren.

6. Infektion vor 24 Tagen. Beobachtung 1 Tag nach dar subcutanen Injektion von $2,5 \mathrm{ccm}$ Tuberkulol. 
Es fallen sofort hier und da kleine Ekchymosen auf.

Mikroskopisch: Auffällig erweiterte Strombahn und stark verlangsamte Strömung. Ziemlich zahlreiche Ekchymosen und Stasecapillaren.

Berieselung mit Suprareninlösung: Nach 3 Minuten allgemeine Stase.

Kochsalzlösung: Die Strömung kommt allmählich wieder in langsamen Gang.

Die Sektion hat bei allen Tieren auch außerhalb des Duodenalmesenteriums Tuberkel an anderen Stellen des Bauchfelles und im Netz nachgewiesen.

Aus den Versuchen an ges unden Tieren geht hervor, daß von einer gewissen Konzentrationsstärke an Tuberkulollösungen eine schwache Einwirkung auf ein mit ihnen berieseltes Stromgebiet besitzen, indem sie eine leichte Constrictorenreizung ausüben oder eine bestehende Verlangsamung steigern, Folgen, die durch Berieselung mit Kochsalzlösung rasch zu beseitigen sind.

Die subcutane Injektion von Tuberkolollösungen verschiedener Stärke hat auf die 4-24 Stunden später mikroskopisch untersuchte Strombahnweite und Strömungsgeschwindigkeit im Mesenterium keinen sichtbaren Einfluß ausgeübt, wohl aber hat sie sehr früh, schon 24 Stunden nach der Injektion, die Empfänglichkeit gegenüber Suprarenin als starkem Constrictorenreiz deutlich herabgesetzt. Statt sofortigen Verschlusses der sehr kleinen Arterien auf längere Zeit trat erst nach einiger Zeit eine Verengerung, einmal auch Verschluß, auf kurze Zeit auf, in einem Versuch von leichter Erweiterung gefolgt; in den Versuchen, in denen während der Suprareninberieselung selbst nur Verengerung eingetreten war, hat sich Verschluß nach Ubergang zur Berieselung mit Kochsalzlösung eingestellt, d. h. also nachdem mit dem Wechsel der Berieselungsflüssigkeit ein neuer Reiz gesetzt worden war.

Die Versuche mit Tuberkulol an tuberkulösen Tieren haben in den 2 Versuchen, wo Berieselung angewandt worden ist, kein übereinstimmendes Resultat gegeben; einmal keine Wirkung, einmal eine starke, nämlich Verengerung, gefolgt von Verlangsamung, die sich stellenweise zur Stase steigerte, im ersten Falle bei Anwendung einer stärkeren Dosis 9 Tage, im 2. Falle bei schwächerer Dosis etwas früher, 8 Tage nach der Infektion. Es hätte einer größeren Reihe von Versuchen bedurft, diesen Gegensatz aufzuklären, wir haben vorgezogen, die Wirkung des subcutan injizierten Tuberkulols an der tuberkulösen Stelle des Mesenteriums genauer zu untersuchen.

Dabei hat sich ergeben, daß, wenn die Dosis des Tuberkulols eine gewisse Höhe $(1,5 \mathrm{ccm})$ erreicht oder überschritten hatte und eine gewisse Zeit (mindestens 12 Tage) seit der Infektion verflossen war, zu dieser Zeit, in der nach Maßgabe der früheren Versuche bei der mikroskopischen Untersuchung an Weite und Geschwindigkeit nichts auffälliges mehr hätte nachweisbar sein dürfen, die Strombahn aufs stärkste erweitert, die Blutströmung aufs stärkste, bis zur Stase und Ekchymosenbildung, verlangsamt war. 
Es folgen nun die mit Tuberkulin angestellten Versuche.

Wir haben Tuberkulin-Merck für die kleinen subcutan gegebenen Dosen, dagegen, um vor einer Nebenwirkung des im Tuberkulin enthaltenen Glycerins geschützt zu sein, Tuberculinum siccum (Höchst) $(0,01 \mathrm{~g}=$ $1 \mathrm{ccm}$ Alttuberkulin) für die größeren Dosen verwandt, desgleichen ausschließlich für Herstellung der zur Berieselung dienenden Lösungen.

A. Versuche an gesunden Tieren.

I. Berieselung des Duodenalmesenteriums mit Lösungen von Tubereulinum siccum.

1. 0,01 : 25 auf 7 Minuten mit nachfolgender Kochsalzberieselung: keine Einwirkung.

2. 0,1 : 25,0 auf 10 Minuten mit nachfolgender Kochsalzberieselung: Nach 1 Minute leichte Verengerung der Arterie und Capillaren, Verlangsamung des Venenstromes. Nach 5 Minuten stärkere Verengerung der Arterie und Capillaren, Venenstrom stark verlangsamt. Nach 10 Minuten langer Einwirkung der Kochsalzlösung ist die Strömung und Weite wieder wie vor dem Versuch.

3. 1,0:25,0 a uf 8 Minuten mit nachfolgender Kochsalzberieselung: Derselbe Verlauf wie im 2. Versuch mit unwesentlichen zeitlichen Differenzen.

II. Subcutane Injektion von Tuberkulin, ein- oder mehrmalig, mikroskopische Untersuchung des Duodenalmesenteriums, Reaktionsversuch mit Suprareninlösung.

a) Mehrfache Injektionen.

1. 4 Dosen $(0,04 ; 0,05 ; 0,06 ; 0,08$, zusammen $0,23 \mathrm{ccm})$ in 7 Tagen. 2 Tage nach der letzten Injektion: Kein auffälliger Befund an Weite und Geschwindigkeit. Berieselung mit Suprareninlösung: Sofortiger Verschluß der Arterien und Capillaren, Stillstand des Venenblutes (wie beim normalen Tier).

2. 5 Dosen (à 0,1 ), zusammen 0,5 in 9 Tagen. 4 Tage nach der letzten Injektion: Nichts auffälliges an Weite und Geschwindigkeit.

Berieselung mit Su prareni nlös ung: Fast sofortiger Verschluß einer kleinen Arterie $(1+)$, leichte Verengerung einer größeren Arterie $(3+)$. Nach 11/4 Minute die Äste dieser größeren Arterie ebenfalls verschlossen, die Arterie selbst auf $1^{1 / 4}$ verengt. Nach $2^{1 / 4}$ Minute ist die größere Arterie wieder etwas weiter, sonst derselbe Befund.

Berieselung mit Kochsalzlösung: Nach 2 Minuten ist auch die größere Arterie verschlossen.

3. 9 Dosen, zusammen 0,5, in 13 Tagen: Der am Abend des Tages der letzten Injektion angestellte Versuch verlief in allen Einzelheiten fast ebenso wie der 2. Versuch.

b) Einmalige Injektion.

4. I ccm Tuberkulin. Am Tage darauf Berieselung mit Su prareninlös ung: Sofortiger Verschluß der Arterien und Capillaren, Stillstand des Venenblutes (wie beim normalen Tier).

5. $1 \mathrm{ccm}$ Tuberkulin: 9 Tage später Berieselung mit Suprareninlösung: Sofortiger Verschluß der Arterien und Capillaren, Stillstand des Venenblutes (wie beim normalen Tier).

6. $1 \mathrm{ccm}$ Tuberkulin. Am Tage nach der Injektion Berieselung mit Su prare. ninlösung: In der ersten halben Minute wechseln Verengerung und Erweiterung der beiden eingestellten Arterien ab. Nach 1 Minute Verschluß der kleineren, Verengerung der (ein wenig) größeren Arterie; nach $1 \frac{1 / 2}{2}$ Minute ist auch diese verschlossen. Nach 3 Minuten ist die größere der beiden Arterien wieder etwas durchgängig. 
Berieselung mit Kochsalzlösung: Der Verschluß löst sich, die Verengerung nimmt $a b$, so daß eine verengte Strombahn mit entsprechend verlangsamter Strömung bestehen bleibt.

7. 2,5 ccm Tuberkulin. Am Tage darauf Berieselung mit Suprareninlösung: Fast momentaner Verschluß der meisten Capillaren, deutliche Verlang. samung des Venenstromes. Nach 1 Minute Arterie streckenweise deutlich verengt. Nach 2 Minuten Arterie ebenso, die Capillaren wieder durchströmt, der Venenstrom langsam. Nach 4 und 5 Minuten Capillaren wieder verschlossen, Arterie in einer Strecke sehr stark, in einer anderen leicht verengt.

Berieselung mit Kochsalzlösung: Verschluß der verengt gewesenen Arterienstrecke, starke Verengerung der übrigen Strecke; Capillaren nicht verschlossen, Venenstrom sehr träge. Nach 2 Minuten Arterie fast ganz verschlossen, ebenso die meisten Capillaren. Der Venenstrom pende]nd. Nach 3 Minuten der gleiche Befund.

B. Versuche an tuberkulösen Tieren.

I. Nach subcutaner Injektion von Tuberkelbacillen am Unter. schenkel.

a) Berieselung des Duodenalmesenteriums mit Tuberculinum siccu m $0,04: 100,0$.

1. 10 Tage nach der Infektion mit $0,2 \mathrm{mg}$ Bacillen: Keine Beeinflussung der Weite und Geschwindigkeit.

2. II Tage nach der Infektion mit 0,2 mg Bacillen: Nach 4 Minuten langer Berieselung Verlangsamung der gesamten Blutströmung, bei leichter Erweiterung der Gefäße und Capillaren.

3. $18 \mathrm{Tage}$ nach der Infektion mit $0,2 \mathrm{mg}$ Bacillen: Derselbe Verlauf, jedoch ist die Verlangsamung stärker. lösung.

b) Berieselung des Duodenalmesenteriums mit Suprarenin-

a) Kleinere Dosis der injizierten Bacillen $(0,2 \mathrm{mg})$.

1. 1 Tag nach der Infektion: Nach einigen Sekunden viele Capillaren verschlossen, Arterie (2) stark verengt, Venenstrom (entsprechend) verlangsamt. Nach 45 Sekunden Arterie verschlossen, Venenstrom stark verlangsamt.

2. 2 Tage nach der Infektion: Nach einigen Sekunden Verengerung der Arterie $(2+)$ und der Capillaren, Venenstron (entsprechend) verlangsamt. Nach 11/4 Minute hat die Arterie wieder nahezu die ursprüngliche Weite, die Capillaren haben wieder die Ausgangsweite, der Venenstrom nur leicht verlangsamt. In den folgenden Minuten mit kaum merklichen Schwankungen derselbe Befund.

Berieselung mit Kochsalzlösung: Die Arterie verengt sich auf $1 \frac{1}{2}$ und zwar ungleichmäBig; viele Capillaren stark verengt; Venenstrom deutlich verlangsamt. Nach $1 \frac{1}{4}$ Minute: Die noch immer ungleichmäßig verengte Arterie mißt an der engsten Stelle 1; nur noch in einigen Capillaren Strömung. Venenstrom stark verlangsamt. - Dieser Befund hält sich in den folgenden Minuten.

3. 5 Tage nach der Infektion.

Im wesentlichen derselbe Verlauf des Versuches wie beim vorigen (2.) Tier.

4. 8 Tage nach der Infektion.

Während 4 Minuten langer Berieselung keine Änderung der Weite und Geschwindigkeit.

Berieselung mit Kochsalzlösung: Leichte Verlangsamung der Strömung, keine Änderung der Weite außer Verengerung einiger Capillaren.

5. 14 Tage nach der Infektion.

Nach $1 / 2$ Minute Arterie für kurze Zeit verengt, Venenstrom (entsprechend) verlangsamt. Nach 1 Minute hat die Arterie wieder die Ausgangsweite, der Venen- 
strom noch verlangsamt. Nach $\mathbf{1}^{3} / 4$ Minuten Arterie stark verengt, das Blut in den verengten Capillaren und in der (nicht verengten) Vene steht fast still.

Berieselung mit Kochsalzlösung: Völliger Verschluß der Arterie und Capillaren.

Die Sektion der 5 Tiere ergab weder makro- noch mikroskopisch etwas Besonderes; nur bei dem 3 . Tiere (5 Tage nach der Infektion getötet) fand sich an der Injektionsstelle ein linsengroßer Absceß mit zahlreichen Tuberkelbacillen.

B) Größere Dosis $(0,4 \mathrm{mg})$ der injizierten Bacillen.

6. 2 Tage nach der Infektion: Nach 20 Sekunden ist die Arterie ( $1 \frac{1 / 2}{2}$ streckenweise stark verengt, der Venenstrom verlangsamt. Nach 45 Sekunden sind die von der beobachteten, jetzt 1 messenden Arterie ausgehenden Äste verschlossen, desgleichen viele Capillaren; der Venenstrom stark verlangsamt. Nach 2 und $3 \mathrm{Mi}$ nuten derselbe Zustand.

Berieselung mit Kochsalzlösung: Nach 1 Minute ist die Arterie fast ganz verschlossen: nur vereinzelte Capillaren noch durchströmt.

7. 4 Tage nach der Infektion: Nach 1 Minute Verlangsamung des Stromes in der Arterie (2) und Vene (3). Nach 1//2 Minuten Verengerung einer Strecke der Arterien, da wo sie in das Pankreas eintritt. Nach 3 Minuten der gleiche Zustand.

Berieselung mit Kochsalzlösung: Nach 11/2 Minuten Arterie an der angegebenen Strecke verschlossen, ebenso die Pankreascapillaren. Vor der verschlossenen Strecke steht das Arterienblut still, das Venenblut pendelt. Nach 3 Minuten der gleiche Zustand.

8. 25 Tage und

9. 28 Tage nach der Infektion: In beiden Versuchen nach schnell vorübergehender leichter Verengerung allgemeine Stase in einem Zeitraum von einigen Minuten.

Die inneren Organe bei diesen 4 Tieren makroskopisch unverändert, desgleichen die Injektionsstelle.

Die mikroskopische Untersuchung der leicht vergrößerten Knielymphdrüse und der Leistendrüsen hat in den drei ersten Versuchen dieser Gruppe keine tuberkulösen Veränderungen ergeben; Tuberkelbacillen nicht nachweisbar. Im vierten Versuch diffuse großzellige Hyperplasie der Knielymphdrüse und einige kleinste Tuberkel aus epithelioiden Zellen mit Riesenzellen; Bacillen äußerst spärlich. - Milz, Leber, Nieren und Lungen ohne Tuberkel.

II. Nach Infektion des Duodenalmesenteriums durch Benetzung (in der früher beschriebenen Weise) frühestens vom 7. Tage ab mehrmalige subcutane Injektion von Alttuberkulin. Mikroskopische Untersuchung des Duodenalmesenteriums.

1. Erste Tuberkulininjektion 10 Tage nach der Infektion. In 11 Tagen 7 Injektionen (von $0,002 \mathrm{ccm}$ auf $0,1 \mathrm{ccm}$ ansteigend, im ganzen $0,254 \mathrm{ccm}$ Tuberkulin). Beobachtung 21 Tage nach der Infektion, 6 Stunden nach der letzten Injektion.

Makrosko pisch: Zahlreiche Tuberkel im gleichmäßig getrübten und leicht verdickten Duodenalmesenterium.

Mikroskopisch: Zahlreiche Tuberkel, teils scharf, teils verwaschen begrenzt, z. T. von Capillaren durchzogen. Ziemlich gleichmäßiges weitmaschiges Netz neugebildeter Capillaren. Strömung überall rasch, nirgends Stase oder Ekchymosen.

Berieselung mit Su prareninlösung: Innerhalb von 2 Minuten, ohne Änderung der Weite der Arterie $\left(1^{1 / 2}\right)$, zunehmende Verlangsamung der Strömung.

Berieselung mit Kochsalzlösung: Nach $3 / 4$ Minuten allg̨emeine Stase; Arterie $1 \frac{1}{2}$. 
2. Erste Tuberkulininjektion 9 Tage nach der Infektion. In 9 Tagen 5 Injektionen von je $0,2 \mathrm{ccm}$ Tuberkulin, im ganzen $1 \mathrm{ccm}$. Beobachtung 18 Tage nach der Infektion, 6 Stunden nach der letzten Injektion.

Makroskopisch: Duodenalmesenterium etwas trüb, mit einer Anzahl kleiner grauer Tuberkel.

Mikroskopisch: Die Tuberkel scharf begrenzt, an vielen Stellen große diffuse Zellanhäufungen. Beträchtliche, wenn auch nicht gleichmäßige Capillarneubildung. Die Strombahn weit, vorwiegend langsam durchströmt. In einer genauer beobachteten Arterie und Vene besteht bald langsame Strömung, bald stockt dieselbe. In ganzen Gesichtsfeldern besteht Stase, auch ältere, bereits mehr oder minder entfärbte. Eine Anzahl ältere (mehr oder minder entfärbte) und zahlreichere frische Ekchymosen.

3. Erste Tuberkulininjektion 10 Tage nach der Infektion. In 17 Tagen 10 Injektionen von 0,0002 auf $0,5 \mathrm{ccm}$ steigend, im ganzen $1,0354 \mathrm{ccm}$. Beobachtung 27 Tage nach der Infektion, 6 Stunden nach der letzten Injektion.

Makroskopisch: Zahlreiche kleine graue Knötchen. Zahlreiche Ekchymosen.

Mikroskopisch: Zahlreiche, scharf abgesetzte Tuberkel. Überall deutlich verlangsamter Blutstrom. Zahlreiche Stasecapillaren und Ekchymosen, und zwar, wie aus den Differenzen der Farbe hervorgeht, frische und ältere.

Berieselung mit Tuberculinum siccum 0,04 : 100,0: Während der 5 Minuten dauernden Berieselung zeitweilig verstärkte Verlangsamung der Strömung.

Berieselung mit Kochsalzlösung: Nach 2 Minuten Strom in der eingestellten stark geschlängelten Vene stark verlangsamt, fast bis zum Stillstand. Nach 3 und 4 Minuten ist die zugehörige Arterie leicht verengt, die Strömungsgeschwindigkeit wechselt.

4. Erste Tuberkulininjektion 7 Tage nach der Infektion. In 17 Tagen 9 Injektionen, von 0,00002 auf $0,4 \mathrm{ccm}$ steigend, im ganzen $1,04446 \mathrm{ccm}$. Beobalhtung 24 Tage nach der Infektion, $6 \mathrm{Stunden}$ nach der letzten Injektion.

Makroskopisch: Zahlreiche kleine graue Knötchen.

Mikroskopisch: Zahlreiche, scharf begrenzte Tuberkel. Beträchtliche Capillarneubildung. Die größeren Gefäße flott durchströmt, in den mittleren und kleineren ist der Stróm stark verlangsamt. Die Gefäße weit. Sehr zahlreiche ältere und frischere Stasecapillaren.

5. Erste Injektion 7 Tage nach der Infektion. In 14 Tagen 6 Injektionen, von 0,2 auf $1,0 \mathrm{~cm}$ steigend, im ganzen $4 \mathrm{ccm}$. Beobachtung 22 Tage nach der Infektion, $24 \mathrm{Stunden}$ nach der letzten Injektion.

Makroskopisch: Im leicht getrübten Duodenalmesenterium zahlreiche kleinste graue Knötchen.

Mikroskopisch: Zahlreiche, häufig nicht ganz scharf begrenzte Tuberkel, teils ohne, teils mit Capillaren. Starke Capillarneubildung. Alle Gefäße, auch die entfernt von Tuberkeln liegenden, äußerst langsam durchströmt. Zahlreiche Stasecapillaren in Tuberkeln. Hier und da meist etwas ältere Ekchymosen.

Berieselung mit Tuberculinum siccum 0,04: 100,0: Bei fast 7 Minuten währender Berieselung keine Änderung des beschriebenen Zustandes.

Bei der Sektion dieser 5 Tiere sind zahlreiche Tuberkel auch an anderen Stellen des Bauchfelles gefunden worden. Die inneren Organe ohne auffälligen Befund.

Aus den Protokollen über die Tuberkulinversuche ergibt sich folgendes, und zwar zunächst für die Anwendung bei ges unden Tieren. 
Berieselung mit Tuberkulinlösungen wirkt von einer bestimmten Stärke an als Constrictorenreiz; diese Reizwirkung verschwindet rasch bei Wiederaufnahme der Berieselung mit Kochsalzlösung.

Mehrfache subcutane Injektionen ändern zwar die Weite und Geschwindigkeit an der Mesenterialstrombahn nicht sichtbarlich, aber bei einer gewissen Gesamthöhe der Dosis $(0,5)$ ist nach 9 und 13 Tagen die Erregbarkeit der Constrictoren herabgesetzt, so zwar, daß sich Arterien eines bestimmten Kalibers, die sich am unbehandelten Tier auf Suprarenin sofort verschlossen hätten, beträchtlich verspätet verschließen.

Dieselbe Wirkung kann durch die einmalige Injektion einer großen Dosis erzielt werden.

Nicht nur in der Verspätung, sondern auch in der ungleichmäßigen und unregelmäßigen Art der Verengerung und des Verschlusses der Arterien und Capillaren verrät sich der atypische Charakter der Suprareninwirkung auf die Gefäßnerven, wenn diese unter Tuberkulineinwirkung stehen.

Anders wirkt das Tuberkulin, wenn es bei tuberkulösen Tieren angewandt wird. Die erste Gruppe von Versuchen hat sich auf Tiere bezogen, denen am Unterschenkel eine geringe Menge Tuberkelbacillen injiziert worden waren.

Bei solchen Tieren hat die mit Lösungen von 0,04\% (Tuberculinum siccum) vorgenommene Berieselung des Mesenteriums 11 und 18 Tage nach der Infektion Erweiterung der Strombahn und Verlangsamung der Blutströmung herbeigeführt.

Wurde bei den auf die angegebene Weise infizierten Tieren Suprareninlösung als Reagens an der Strombahn des Duodenalmesenteriums benutzt, so ist in 9 Versuchen regelmäßig, mochte eine kleinere oder größere Menge von Bacillen am Unterschenkel injiziert worden sein, die normale Suprareninwirkung auf kleine Arterien - sofortiger Verschluß auf längere Zeit - ausgeblieben, und es hat sich vom Ende des 1. Tages an bis zum 28. Tage nach der Infektion entweder eine Verspätung der Verengerung und des Verschlusses oder Ausbleiben jeglicher Verengerung (am 8. Tage nach der Infektion mit der kleinen Bacillenmenge), oder Ausgang der abgeschwächten Reaktion in Stase (25 und 28 Tage nach der größeren Bacillendosis) ergeben. Dabei sind wieder eine Reihe von Eigentümlichkeiten des Kontraktionsvorganges, wir heben aus den Protokollen besonders die segmentäre Verengerung hervor, beobachtet worden, die man am normalen Tier nie feststellen kann.

Es ist in diesen Versuchen nicht gelungen - mit einer Ausnahme, wo die Knielymphdrüse tuberkulös war- makroskopisch und, soweit die Untersuchung ein Urteil zuließ, mikroskopisch nachweisbare tuberkulöse Gewebsveränderungen hervorzurufen, wenn es auch so gut wie sicher sein dürfte, daß die Injektion eines nicht unbedeutenden Quan- 
tums virulenter Bacillen in diesem oder jenem Organ des Körpers Tuberkel hat entstehen lassen.

Die Einwirkung mehrfacher subcutaner Tuberkulininjektionen auf das vorher tuberkulös gemachte Mesenterium haben wir in den 5 Versuchen der letzten Gruppe untersucht.

Diese haben gezeigt, daß nur im ersten Versuche - mit der kleinsten Dosis und der frühesten Besichtigung - die Weite und Geschwindigkeit für das Auge unbeeinflußt geblieben war, bei Aufhebung der Erregbarkeit der Constrictoren durch Suprarenin, das, nach dem Utbergange zur Kochsalzberieselung, allgemeine Stase auslöste. In den übrigen Versuchen, in denen zusammen $1 \mathrm{ccm}$ Tuberkulin und mehr subcutan verabfolgt worden war, war im tuberkelhaltigen Mesenterium das zu dieser Zeit nach der Infektion flotten Blutstrom ohne Erweiterung der Strombahn hätte zeigen müssen - die Strömung in der erweiterten Strombahn stark verlangsamt bis zu mehr oder weniger ausgedehnter Stase und Infarzierung; auch schon vor der Besichtigung war hier und da Stase und Ekchymosenbildung aufgetreten.

In diesem Zustande der Strombahn vorgenommene Tuberkulinberieselung hat einmal leicht verlangsamend, einmal überhaupt nicht ändernd eingewirkt.

Aus den soeben besprochenen Versuchen des zweiten Hauptteiles unserer Abhandlung hat sich folgendes ergeben.

Tuberkulol B und Tuberkulin wirken von einer gewissen Höhe der Konzentration ab lokal angewandt als Gefäßnervenreize am Mesenterium ges under Kaninchen und zwar als Constrictorenreiz, während Dilatation mit Verlangsamung auch durch starke Dosis nicht zu erzielen ist.

Subcutan verabfolgt setzen Tuberkulol und Tuberkulin, wieder bei Anwendung in einer bestimmten Stärke, die Erregbarkeit der Constrictoren im Mesenterium gesunder Tiere herab. Im tuberkulösen Mesenterium außerdem - nach vorausgegangener Reizung - die der Dilatatoren, so daß sich die Strömung in der erweiterten Strombahn verlangsamt und in einem großen Teil derselben erlischt.

Es hat sich aus den Versuchen weiter ergeben, daß sich das Gefäßnervensystem von Tieren, die mit Tuberkelbacillen infiziert sind, an Orten, wo tuberkulöse Veränderungen fehlen, gegenüber experimentell gesetzten lokalen Reizen, mögen sie von Tuberkelbacillen stammen (Tuberkulin) oder ganz andersartig (Suprarenin) sein, in ähnlicher Weise abweichend verhält, so daß also diese Reize bei den infizierten Tieren zu bestimmter Zeit nach der Infektion keine Verengerung, sondern Erweiterung mit Verlangsamung hervorrufen. 
Im ersten Hauptteil haben wir als das Ergebnis von Experimenten angegeben, daß im Vergleiche zu der Konstriktion der Strombahn ihrer mit Verlangsamung verbundenen Erweiterung eine stärkere Form der Reizung entspricht; wir dürfen somit dem Tuberkulol und Tuberkulin eine stärkere Beeinflussung der Gefäßnerven im tuberkulösen Gewebe zuschreiben als im normalen.

Wir gehen nun dazu über, die gewonnenen Ergebnisse zur Erläuterung der Tuberkulinwirkung zu verwenden.

R. Koch fand bei tuberkulösen Meerschweinchen, die durch Tuberkulin getötet waren, folgende Veränderungen : starke bis violette Rötung der Impfstelle, ihrer Umgebung und der zugehörigen Lymphdrüsen, dunkelrote (,schwärzlich-rote") bis hanfkorngroße Flecken an der Oberfläche der Milz und Leber, denen ,eine enorme Erweiterung der Capillaren" in der nächsten Umgebung der Tuberkel zugrunde lag: ,die Capillaren sind vollgestopft mit roten Blutkörperchen, daß es so aussieht, als sei hier der Blutstrom zum vollständigen Stillstand gekommen"; ausnahmsweise waren die roten Flecke Ekchymosen. Ähnliche Veränderungen, wenn auch weniger regelmäßig und ausgesprochen, traf Koch in den Lungen der Tiere an.

Die beschriebenen Befunde sind dieselben, die wir nach subcutaner Verabfolgung von Tuberkulin unter dem Mikrokops beim lebenden und getöteten Tier in der nächsten und weiteren Umgebung der Tuberkel beobachtet und als Wirkung des Tuberkulins auf die Gefäßnerven nachgewiesen haben. Während also in dem grundlegenden Kochschen Versuche das Tuberkulin in größerer Entfernung von den Tuberkeln die Gefäßnerven unbeeinflußt gelassen hatte, so daß daselbst die Constrictoren erregbar geblieben waren und ihre beim Sterben zustande kommende Reizung zur Entleerung des Blutes in die Venen geführt hatte, hatte in der Nähe der Tuberkel unter dem Einfluß der Tuberkelbacillen und ihrer Produkte nach Aufhebung der Erregbarkeit der Constrictoren eine Dilatatorenreizung mit Verlangsamung des Blutstromes bestanden, die sich infolge der Tuberkulinverabfolgung gesteigert und mit Stase geendigt hatte. Diese von Koch in der Leiche durch Tuberkulin getöteter tuberkulöser Tieren entdeckte ,Tuberkulinreaktion“ ist somit der Ausdruck der von uns eingehend studierten erhöhten Empfindlichkeit der Gefäßnerven in tuberkulösem Gewebe.

Die örtliche Tuberkulinreaktion zu diagnostischen Zwecken am Tier und Menschen wird mit subcutaner Injektion kleiner Dosen von Tuberkulin erzielt und nach Koch am besten am Lupus studiert. Nach seiner Schilderung beobachtet man an der lupösen Stelle Rötung und Schwellung, die immer mehr zunehmen und schließlich einen ganz bedeutenden Grad erreichen, „so daß das Lupusgewebe stellenweise braunrot und nekrotisch wird“" „An schärfer abgegrenzten Lupusherden war öfters 
die stark geschwollene und braunrot gewordene Stelle von einem weißlichen, fast einen Zentimeter breiten Saum eingefaßt, der seinerseits wieder von einem lebhaft gerötetem Hof umgeben war.“ „,Die Lupusherde selbst haben sich mit Kruste von aussickerndem und an der Luft vertrocknetem Serum bedeckt, sie verwandeln sich in Borken, welche nach zwei bis drei Wochen abfallen." Die histiologische Forschung hat diesen Befund dahin ergänzt, daß im Bereich und in der Umgebung der Knötchen eine Extravasation von teilweise zu Fibrin gerinnender Flüssigkeit und von weißen Blutkörperchen statthat.

Wir haben in der Reaktion des Lupus auf Tuberkulin wieder den Ausdruck der stärkeren Beeinflußbarkeit der Gefäßnerven eines tuberkulösen Gebietes durch Tuberkulin vor uns und zwar im Vergleich zu dem, was sich in der Umgebung der Tuberkel eines durch Tuberkulin getöteten Tieres abspielt, die Wirkung einer schwächeren Reizung jener Nerven. Hat sich doch aus den Experimenten ergeben, daß schwächere Reize diejenige Form der Reizung der Dilatatoren und der Verminderung des Einflusses der Gefäßnerven auf die Arbeitsleistung der Strombahnwand hervorrufen, bei der das Blut unter Randstellung der weißen Blutkörperchen verlangsamt fließt und diese samt Flüssigkeit nach außen treten läßt, während stärkere Reize die stärkere Verlangsamung herbeiführen, bei der die Extravasation von Leukocyten und die Exsudation unterbleiben und die nach Verlust der Erregbarkeit der Gefäßnerven in Stase übergeht. Es ist nur natürlich, daß die kleinere Dosis von Tuberkulin den akutentzündlichen Typus der Stromverlangsamung im Lupus -, die größere Dosis die Stase hervorruft, die Koch an den Tuberkeln der durch Tuberkulin getöteten Tiere gefunden hatte.

Daß der Tuberkulinreaktion am tuberkulösen Herde eine Reizung der Gefäßnerven zugrunde liegt, wird besonders klar beleuchtet durch die oben erwähnte Erfahrung Kochs, daß um den in der angegebenen Weise durch Tuberkulin beeinflußten Tuberkel zunächst ein blasser, dann ein lebhaft roter Hof herumgehen kann. Es ergibt sich aus unseren einleitenden allgemeinen Bemerkungen, daß die nächst geringere Reizwirkung in Constrictorenerregung und die geringste in Dilatatorenreizung bei Erhaltensein der Erregbarkeit der Constrictoren - ohne Erregung derselben durch den zu schwachen, nur die Dilatatoren ansprechenden Reiz - besteht, während deren das Blut in der erweiterten Strombahn beschleunigt, also lebhaft gerötet, fließt. Wir haben somit am Tuberkel und seinen Capillaren und an den Capillaren und Gefäßchen seiner näheren und weiteren Umgebung eine Abstufung der Reizwirkung des Tuberkulins vor uns, die aufs strengste den Gesetzen über Reizung der Gefäßnerven entspricht, wie sie die experimentelle Physiologie und Pathologie ermittelt haben.

Ähnlich wie sie besonders am Lupus mit unbewaffnetem Auge und mit 
Hilfe des Mikroskops bekannt gew orden ist, verläuft die Tuberkulinreaktion zweifellos an den inneren Organen. Stets handelt es sich um Rötung und Schwellung, um Hyperämie des mit Extravasation weißer Blutkörperchen und mit Exsudation verbundenen Typus der Dilatatorenreizung, nicht selten mit Schmerzhaftigkeit einhergehend.

Die enge Beziehung zwischen den beiden Typen der Stromverlangsamung, der akut entzündlichen und der mit Stase endigenden, macht es begreiflich, daß im Verlauf der Tuberkulinreaktion beide nebeneinander bestehen können. Es wird denn auch mitgeteilt, daß nach subcutaner Tuberkulininjektion zu diagnostischen Zwecken im tuberkulösen Gebiet Blutungen auftreten können, z. B. in den Lungen, indem blutiger Auswurf, in den Nieren, indem Blutharn beobachtet worden ist. Da bei beiden Typen der Stromverlangsamung das Blut auf die Dauer zum Stillstand kommen kann, so ist es weiter verständlich, wenn als seltener, stärkster Effekt im Verlauf einer Tuberkulinreaktion oder im Anschluß an dieselbe Nekrose, z. B. Ulceration eines Lupus, Aufbruch einer Fistel, eintritt, ein Gewebszerfall, wie er sich überall da einstellt, wo die Blutströmung aufgehoben wird.

Wenn man somit von verschiedenen Graden der Tuberkulinreaktion sprechen kann, so werden dieselben von dem verschiedenen Charakter der von dem Mittel im einzelnen Falle hervorgebrachten Reizwirkung auf die Gefäßnerven bestimmt. Die Ursachen dieser Unterschiede sind zweifellos mannigfaltig, indessen wird eine derselben auch durch unsere Versuche in ein helles Licht gesetzt, nämlich der Einfluß des verschiedenen Alters der tuberkulösen Gewebsveränderungen; haben wir doch gesehen, daß eine bestimmte Zeit seit der Infektion verflossen sein muß, auf $\mathrm{da} B$ die Reaktion in maximaler Stärke eintritt. In dieser Hinsicht ist es bemerkenswert, daß die lokale Beeinflussung der Gefäßmerven des tuberkulösen Gewebes durch Mittel, wie Suprarenin u. a., die sonst Konstriktion, hier aber Dilatation und Stase erzeugen, mit dem Fortschritt der Zeit seit der Infektion abnimmt, daß also ein Gegensatz zu der Beeinflußbarkeit der Gefäßnerven des tuberkulösen Herdes durch subcutane Injektion von Tuberkulin an entfernter Körperstelle besteht. - Die Aufklärung dieser merkwürdigen Tatsache muß weiteren Versuchen vorbehalten bleiben.

Wir kommen nun zu den Tuberkulinreaktionen, die in normalem Gewebe dann auftreten, wenn sich im Körper ein tuberkulöser Herd befindet. Als Grundlage ihres Verständnisses sehen wir die von uns in zahlreichen Tierversuchen nachgewiesene Tatsache an, daß die Gefäßnerven auch außerhalb eines tuberkulösen Gebietes gegen lokal applizierte Reize abnorm reagieren, wie anderen Mitteln, so Tuberkulol und Tuberkulin gegenüber.

An erster Stelle hat hier die v. Pirq uetsche unblutige Cutanimpfung 
mit Alttuberkulin zu stehen. Die durch das Tuberkulin bewirkte Reaktion an der Impfstelle und ihrer Umgebung besteht in Hyperämie mit Exsudation von Flüssigkeit und Extravasation weißer Blutkörperchen in Form einer Papel, während sich an der ebenso mechanisch lädierten, aber nicht mit Tuberkulin benetzten Kontrollstelle dieselben Vorgänge in weit geringerer Stärke abspielen, so daß keine Papel entsteht. Es kann nach unseren Tierversuchen und den aus ihnen gezogenen Folgerungen nicht zweifelhaft sein, daß wir es in der v.Pirq u etschen Reaktion mit dem oft erwähnten Reizungs- und Erregbarkeitszustande der Gefäßnerven zu tun haben, von dem Erweiterung der Strombahn und Verlangsamung der Blutströmung mit Exsudation und Extravasation abhängig sind, und daß diese Reizungsfolgen bei einem tuberkulös infizierten Individuum deswegen stärker ausfallen, weil sein Gesamtgefäßnervensystem leichter erregbar ist. Auch die tuberkelähnlichen Bildungen, die nach der v. Pirquetschen Impfung - nach unseren eigenen Erfahrungen sehr selten - auftreten, erklären sich, sofern und soweit nicht Bacillen im Spiele sind, als Wirkung des Tuberkulins in derselben Weise, wie wir es von dem Tuberkel im 1. Teile gesehen haben, um so mehr, als es nach unseren oben wiedergegebenen Beobachtungen keineswegs sicher ist, daß zur Entstehung eines Tuberkels die Gegenwart von Bacillen notwendig ist.

Auf Eintritt und Ausbleiben, sowie Grad der Ausbildung der v. Pirquetschen Reaktion sind, wie die Erfahrung gelehrt hat, mancherlei Einflüsse von Bedeutung; ihre Beziehung zu der konstitutionellen Erregbarkeit des Gefäßnervensystems und ihren Alterationen insbesondere durch Krankheiten, namentlich der Haut, zu erforschen, sehen wir als eine wichtige Aufgabe der experimentellen Forschung am Menschen an ${ }^{1}$ ).

Die von Moro getroffene Modifikation der v. Pirquetschen Reaktion (sogen. Percutanreaktion mit der Moroschen Tuberkulinsalbe) bedarf in ihrem im wesentlichen übereinstimmenden Verlauf keiner weiteren Worte zur Begründung, daß das Tuberkulin am Nervensystem und zwar dem besonders erregbaren des tuberkulös infizierten Körpers angreift. Einer besonderen Erwähnung bedürfen aber die Beobachtungen, die Moro (1908) unter dem Titel ,Tuberkulinreaktion und Nervensystem "2) mitgeteilt hat: 1. Auftreten einer ,kontralateralen Reaktion", an der dem Inunktionsorte symmetrischen Hautstelle,

1) In dieser Hinsicht ist es von Interesse, daß neuerdings (1914) Cronquist (Beobachtungen über den Ablauf der v. Pirquetschen Reaktion bei Kindern, Jahrbuch f. Kinderheilkunde \%9, H. 1) nachgewiesen hat, daß die v. Pirquetsche Reaktion stärker verläuft bei Kindern mit sog. exsudativer Diathese, d. h. bei Kindern, deren Gefäßnervensystem (wie es scheint, unter dem Einflusse von Ernährungsstörungen) eine erhöhte Erregbarkeit besitzt.

2) E. Moro, Klinische U̇̉berempfindlichkeit, Münch. med. Wochenschr. 55, 1908. 
z. B. an der anderen Mamma, 2., ,disseminierte Fernreaktion" der Haut, z. B. nach Inunktion an der Bauchhaut reaktive Hautveränderungen auch an der Brust, am Rücken, am Halse, an Stellen, die mit dem Tuberkulin nicht in Berührung gekommen waren, 3. halbseitige gürtelförmige Mitreaktion der Haut.

Moro schließt aus diesen und anderen Beobachtungen: ,,Der Charakter der Reaktion im Verein mit den vorgeführten Beobachtungen läßt uns die percutane Tuberkulinreaktion im wesentlichen als ein Vasomotorenphänomen erkennen, das durch eine starke Erregung vasodilatatorischer Bahnen zustandekommt.“ ,Es besteht bei tuberkuloseinfizierten Individuen eine spezifische (der Tuberkulose eigentümliche) Reizbarkeit des Nervensystems gegenüber dem Tuberkulin ..."

Moro ist also auf Grund seiner klinischen Beobachtungen zu demselben Ergebnis gekommen, wie wir durch unsere experimentellen Untersuchungen.

Wir können darauf verzichten, unter unserem Gesichtspunkte auch die übrigen auf der Grundlage der v. Pirquetschen Entdeckung geschaffenen Tuberkulinreaktionen ausführlich zu besprechen; es sei nur noch darauf aufmerksam gemacht, daß die Conjunctivalreaktion WolffEisners in ihren verschiedenen Stärkegraden den Utbergang von einfacher Rötung und Schwellung zu Eiterabsonderung und Ekchymosenbildung, die intracutane Reaktion bis zu Stase und Hämorrhagie mit Gewebszerfall erkennen läßt - also die Reihenfolge der Vorgänge, die nach dem physiologischen und pathologischen Experiment bei sich steigernder Reizstärke oder aber bei zunehmender Empfindlichkeit zu erwarten ist. Da man auch an der Schleimhaut der Nase, der Harnröhre, des Mastdarmes, der Scheide, der Luftwege Tuberkulinreaktionen hervorgebracht hat, kann es keinem Zweifel unterliegen, daß der ganze mit Tuberkelbacillen infizierte Körper die erhöhte Reizbarkeit des Gefäßnervensystems besitzt, die der Reaktion zugrunde liegt. Da nichts im Wege steht, auch das Fieber in Abhängigkeit von der Beeinflussung der Gefäßnerven zu bringen, so ist die Gefäßnerventheorie der Tuberkulinreaktion, soviel auch noch im einzelnen auszubauen übrigbleibt, aufs beste gestützt und geeignet, an die Stelle der anderen, Einwänden ausgesetzten und daher auch nicht zur Anerkennung durchgedrungenen Theorien $\mathrm{zu}$ treten.

Es kann hier nicht unsere Aufgabe sein, diese Theorien eingehend zu erörtern, nur soviel möchten wir in Hinweis auf den ersten Teil unserer Abhandlung bemerken, daß eine Tuberkulintheorie, die die Leukocyten in den Vordergrund stellt, im Widerspruch mit der Geschichte des Tuberkels steht, die nur eine vorübergehende und vergleichsweise geringe Rolle der Leukocyten kennt, und daß diejenigen Tuberkulintheorien, die von der Unwirksamkeit des Tuberkulins im gesunden Körper ausgehen, 
gegen unsere Erfahrung verstoßen, daß Tuberkulin ein Gefäßnervenreiz auch im gesunden Körper ist, so daß nur streng gesetzmäßige quantitative Unterschiede zwischen dem Verhalten des gesunden und dem des tuberkulösen Tieres existieren.

Unsere Versuche haben gezeigt, daß die erhöhte Reizbarkeit der Gefäßnerven eines tuberkuloseinfizierten Körpers im Bereich der tuberkulösen Veränderungen und außerhalb derselben nicht nur gegen Tuberkulol und Tuberkulin besteht, sondern auch gegen Suprarenin; dieses Mittel ist lediglich als Repräsentant zahlloser anderer von uns benutzt und aufgefaßt worden und zwar mit Recht, da, wie uns frühere Versuche (Natus, l. e.) gelehrt haben, während eines irgendwie bedingten starken Erregungszustandes der Gefäßnerven und nach einem solchen, wenn die sichtbaren Folgen dieses Zustandes an der Strombahn verschwunden sind, jeder hinzutretende Reiz von einer genügenden Stärke eine stärkere Wirkung hat, als am Gefäßnervensystem eines normalen Körpers. Wirhaben somit allen Grund, uns auf die Seite derer zu stellen, die der Tuberkulinreaktion einen spezifischen Charakter, sowohl in dem Sinne, daß nur Tuberkulin eine Reaktion bei Tuberkulösen hervorruft, als in dem anderen, daß nur Tuberkulöse auf Tuberkulin reagieren, absprechen. Tuberkulin und Tuberkulol wirken, wie unsere Versuche gezeigt haben, auf das Gefäßnervensystem des gesunden und des tuberkuloseinfizierten Körpers, dort schwach, hier stark, und der tuberkulös infizierte Körper ist sowohl gegen Tuberkulin als auch gegen andere Reize besonders empfindlich. Da man zudem auch bei anderen chronisch-infektiösen Krankheiten Tuberkulinreaktion, lokale und allgemeine, beobachtet hat, kann in keinem Sinne von einer Spezifität der Tuberkulinwirkung gesprochen werden.

Der, wie bekannt, nicht einwandfrei nachgewiesene therapeutische Wert des Tuberkulins kann uns hier nur so weit beschäftigen, als unsere Versuche es zulassen. Diese haben gelehrt, daß man mit Tuberkulin Stase in tuberkulösem Gewebe erzielen kann; Stase aber bedingt die Nekrose des zugehörigen Gewebes.

In einer früheren großen Versuchsreihe ${ }^{1}$ ) hat sich herausgestellt, daß bei demjenigen chronischen Reizungszustande, bei dem die Constrictoren in ihrer Erregbarkeit beeinträchtigt, die Dilatatoren erregt sind, und eine Neigung zu Verlust der Erregbarkeit des gesamten Gefäßnervensystems besteht, - ein Typus, wie er die chronische Entzündung charakterisiert - das Bindegewebe infolge der Hyperämie zunimmt. Es ist die Annahme zulässig, daß das Tuberkulin, häufig in den Körper eingeführt, diesen Zustand der Blutströmung als Folge einer chronischen Reizwirkung auf das Gefäßnervensystem des tuberkulösen Stellen benachbarten, mehr oder minder normalen Gewebes herstellt. So würde sich

1) Natus, l. c. (Virchows Archiv 202, 1910). 
Verkäsung und bindegewebige Abkapselung und, nach Resorption oder Abstoßung des Verkästen, die Vernarbung eines tuberkulösen Herdes als Folge von Tuberkulingaben erklären, - desgleichen die Wirkung anderer chemischer oder physikalischer Maßnahmen, denen man, ob mit Recht oder Unrecht mag dahingestellt bleiben, einen therapeutischen Wert zuschreibt.

Eine sorgfältige Durchsicht der Literatur hat uns gelehrt, daß ein großer Teil der Beobachtungen, die wir im vorhergehenden erwähnt haben, bereits von anderen Autoren gemacht worden sind. So ist der akutentzündliche Anfang einer tuberkulösen Infektion an verschiedenen Organen aus den mikroskopischen Befunden erschlossen worden, bei dieser und jener Untersuchung ist man auf Capillaren in Tuberkeln, auch des Bauchfelles, aufmerksam geworden und man hat einerseits an gesunden Tieren durch Tuberkulin funktionelle und Gewebsveränderungen erzengt, andererseits, wie oben erwähnt, die durch das Mittel zu erzielenden Vorgänge, insbesondere die Kreislaufstörung, in tuberkulösem Gewebe makro- und mikroskopisch kennen gelernt. Auch ließen sich Autoren anführen, die wenigstens die Hyperämie in dem primären akutentzündlichen Stadium der tuberkulösen Infektion oder bei der Tuberkulinreaktion auf Pueizung der Dilatatoren zurückgeführt haben, am deutlichsten Moro, dessen wir oben ausführlich gedacht haben. Wollten wir alle hierhergehörigen, meist beiläufig gemachten und nichs naher begründeten Äußerungen hier mitteilen, es gäbe eine lange Reihe Einzelheiten, für die bisher das verbindende Band gefehlt hat und die deswegen auch ohne Eindruck auf die Mit- und Nachwelt geblieben sind. Wir sehen daher von einer literarischen Utbersicht ab und beanspruchen für uns nur, bekannte Befunde bestätigt und wesentlich erweitert und sie zu einer Theorie der Tuberkelbacillen- und Tuberkulinwirkung verarbeitet zu haben in deren Mittelpunkt das GefäBnervensystem steht.

\section{Erklärung der Tafel I.}

Erläuterungen $\mathrm{zu}$ den Abbildungen nach gefärbten Flächenpräparaten des Duodenalmesenteriums, Baçillen nicht eingezeichnet. $\% / 10$ der Originale.

Fig. 1: 2 Tage nach der Infektion durch Injektion. Neugebildete Capillaren. Früheste Tuberkel. - Zeiß, achrom. Obj. AA, Oc. 2, Tubuslänge 150.

Fig. 2: 4 Tage nach der Infektion durch Injektion. Starker Grad von Capillarneubildung. Zwei Tuberkel, der eine capillarfrei. - Zeiß, apochrom. Obj. $f=16$, Oc. 2 , Tubus eingeschoben.

Fig. 3: 21 Tage nach der Infektion durch Injektion. Capillarnetz weitmaschig. Tuberkel und diffuses tuberkulöses Gewebe mit und ohne Capillaren. Zeiß, apochrom. Obj. $f=16$, Oc. 2, Tubus eingeschoben.

Fig. 4: 25 Tage nach der Infektion durch Bepinselung. Mit Capillaren versehener Tuberkel. - Zeiß, apochrom. Obj $f=4$, Oc. 2, Tubuslänge 150. 